\title{
Long-term assessment of airborne radiocesium after the Fukushima nuclear accident: re-suspension from bare soil and forest ecosystems
}

\author{
Mizuo Kajino ${ }^{1,2}$, Masahide Ishizuka ${ }^{3}$, Yasuhito Igarashi ${ }^{1}$, Kazuyuki Kita $^{4}$, Chisato Yoshikawa ${ }^{5}$, and Masaru Inatsu ${ }^{6}$ \\ ${ }^{1}$ Meteorological Research Institute (MRI), Japan Meteorological Agency (JMA), Tsukuba, Ibaraki, Japan \\ ${ }^{2}$ RIKEN Advanced Institute for Computational Science (AICS), Kobe, Hyogo, Japan \\ ${ }^{3}$ Faculty of Engineering, Kagawa University, Takamatsu, Kagawa, Japan \\ ${ }^{4}$ Faculty of Science, Ibaraki University, Mito, Ibaraki, Japan \\ ${ }^{5}$ Japan Agency for Marine-Earth Science and Technology (JAMSTEC), Yokosuka, Kanagawa, Japan \\ ${ }^{6}$ Faculty of Science, Hokkaido University, Sapporo, Hokkaido, Japan \\ Correspondence to: Mizuo Kajino (kajino@mri-jma.go.jp)
}

Received: 29 March 2016 - Published in Atmos. Chem. Phys. Discuss.: 25 April 2016

Revised: 26 July 2016 - Accepted: 19 September 2016 - Published: 27 October 2016

\begin{abstract}
The long-term effect of ${ }^{137}$ Cs re-suspension from contaminated soil and forests due to the Fukushima nuclear accident has been quantitatively assessed by numerical simulation, a field experiment on dust emission flux in a contaminated area (town of Namie, Fukushima prefecture), and air concentration measurements inside (Namie) and outside (city of Tsukuba, Ibaraki prefecture) the contaminated area. In order to assess the long-term effect, the full year of 2013 was selected to study just after the start of the field experiments. The ${ }^{137} \mathrm{Cs}$ concentrations at Namie and Tsukuba were approximately $10^{-1}-1$ and $10^{-2}-10^{-1} \mathrm{mBq} \mathrm{m}^{-3}$, respectively. The observed monthly median concentration at Namie was 1 to 2 orders of magnitude larger than that at Tsukuba. This observed difference between the two sites was consistent with the simulated difference, indicating successful modeling of ${ }^{137} \mathrm{Cs}$ re-suspension and atmospheric transport. The estimated re-suspension rate was approximately $10^{-6}$ day $^{-1}$, which was significantly lower than the decreasing rate of the ambient gamma dose rate in Fukushima prefecture $\left(10^{-4}-10^{-3}\right.$ day $\left.^{-1}\right)$ as a result of radioactive decay, migration in the soil and biota, and decontamination. Consequently, re-suspension contributed negligibly in reducing ground radioactivity. The dust emission model could reproduce the air concentration of ${ }^{137} \mathrm{Cs}$ in winter, whereas the summer air concentration was underestimated by 1 to 2 orders of magnitude. Re-suspension from forests at a constant rate of $10^{-7} \mathrm{~h}^{-1}$, multiplied by the green area fraction, could explain the air concentration of ${ }^{137} \mathrm{Cs}$ at Namie and
\end{abstract}

its seasonal variation. The simulated contribution of dust resuspension to the air concentration was $0.7-0.9$ in the cold season and $0.2-0.4$ in the warm season at both sites; the remainder of the contribution was re-suspension from forest. The re-suspension mechanisms, especially through the forest ecosystems, remain unknown. This is the first study that provides a crude estimation of the long-term assessment of radiocesium re-suspension. Additional research activities should investigate the processes/mechanisms governing the re-suspension over the long term. This could be achieved through conducting additional field experiments and numerical simulations.

\section{Introduction}

The Fukushima Daiichi Nuclear Power Plant (FDNPP) accidentally released nuclear fission products into the atmosphere and the ocean environment following the catastrophic earthquake and tsunami that occurred in March 2011. The accident caused serious contamination of the soil over the Tohoku region (northeastern part of Japan, including Fukushima and Miyagi prefectures) and the Kanto region (eastern part of Japan, including Ibaraki, Tochigi, Gunma, and Chiba prefectures; NRA, 2012). Since then, a number of studies have been conducted, particularly during the months that followed the accident. These assessments include primary emission estimations (Chino et al., 2011; Danielache 
et al., 2012; Stohl et al., 2012; Terada et al., 2012; Katata et al., 2012a, b, 2015; Winiarek et al., 2012, 2014; Hirao et al., 2013; Saunier et al., 2013; Yumimoto et al., 2016; Danielache et al., 2016), field observations (ground aerosol sampling: Masson et al., 2011, 2013; Kaneyasu et al., 2012; Adachi et al., 2013; Tsuruta et al., 2014; Igarashi et al., 2015; Oura et al., 2015; aircraft measurements: NRA, 2012; and measurements carried out on foot: Hososhima and Kaneyasu, 2015), and numerical simulations of transport and depositions (deterministic simulation: Chino et al., 2011; Morino et al., 2011; Yasunari et al., 2011; Stohl et al., 2012; Terada et al., 2012; Katata et al., 2012a, b; Winiarek et al., 2012, 2014; Hirao et al., 2013; Saunier et al., 2013; Katata et al., 2015; Yumimoto et al., 2016; Danielache et al., 2016; deterministic simulation with sensitivity runs: Morino et al., 2013; Adachi et al., 2013; Groëll et al., 2014; Saito et al., 2015; Sekiyama et al., 2015; Quérel et al., 2015; uncertainty modeling and probabilistic forecast: Girard et al., 2016; Sekiyama et al., 2016; and multi-model intercomparison and multi-model ensemble analysis: SCJ, 2014; Draxler et al., 2015; Kristiansen et al., 2016). The targeted radionuclides were species with both short and long half-lives: ${ }^{99} \mathrm{Mo}-{ }^{99} \mathrm{~m}$ Tc (half-life 65.9$6 \mathrm{~h}),{ }^{129 \mathrm{~m}} \mathrm{Te}$ (33.6 days), ${ }^{131} \mathrm{I}$ (8.02 days), ${ }^{132} \mathrm{Te}-{ }^{132} \mathrm{I}(3.2$ days-2.3 h), ${ }^{134} \mathrm{Cs}$ (2.07 years), ${ }^{136} \mathrm{Cs}$ (13.2 days), ${ }^{137} \mathrm{Cs}$ (30.1 years), ${ }^{133} \mathrm{Xe}$ (5.2 days), and ${ }^{35} \mathrm{~S}$ (87.5 days).

In contrast, there have been few studies on the long-term (more than 1 year) quantitative assessment of radioactivity in the atmosphere associated with the Fukushima accident (Igarashi et al., 2015; Ishizuka et al., 2016; Kinase et al., 2016). More than 100000 people were evacuated (METI, 2012), and most have still not been able to return to their homes and the public remains anxious about the safety of the affected areas. Radionuclides with long half-lives such as ${ }^{134} \mathrm{Cs}$ (2.07 years) and ${ }^{137} \mathrm{Cs}$ (30.1 years) are of particular concern (Evangeliou et al., 2014). Following the Chernobyl accident there were several studies on the re-suspension and long-term assessment of these radionuclides, such as Holländer and Garger (1996), Garger et al. (1998), Hatano and Hatano (2003), and Garger et al. (2012). For example, Garger et al. (2012) estimated the re-suspension "descending trend" as having a half-life of 300 days based on the surface activity concentration of ${ }^{137} \mathrm{Cs}$. In the case of the Fukushima accident, Igarashi et al. (2015) estimated the half-reduction time by fitting multi-component exponential functions based on the ${ }^{137} \mathrm{Cs}$ concentration at the Meteorological Research Institute (Tsukuba) as 5.9 days, 16 days, and 1.1 years. These estimates were based on the trend in the observed surface air concentrations of ${ }^{137} \mathrm{Cs}$, and thus the contributions from advection, diffusion, emission, and deposition terms were not quantified.

There are thousands of monitoring posts situated in the contaminated area in Fukushima prefecture to measure the ambient gamma dose rate. However, the data cannot be used for evaluating internal exposure: evaluation of internal exposure requires direct measurement of the surface air ac- tivity concentration. There are only a few observation sites that continuously measure the concentration of radiocesium (e.g., Igarashi et al., 2015; Ishizuka et al., 2016; Kinase et al., 2016). To assess the spatial distribution of the internal exposure hazard, 3-D numerical simulation is necessary to interpolate values for unmonitored locations. The numerical simulation requires emission flux as a boundary condition. However, the mechanism and thus the radioactivity flux associated with the re-suspension of ${ }^{137} \mathrm{Cs}$ were unknown, despite extensive efforts based on field observations (e.g., Igarashi et al., 2015; Ishizuka et al., 2016; Kinase et al., 2016).

Garger et al. (2012) summarized the re-suspension sources following the Chernobyl accident as (1) dust emission, (2) human activity in fields as well as on roads and construction sites, (3) forest fires, and (4) emissions from the power plant (i.e., opening of the Chernobyl sarcophagus). Re-suspension sources (1) (Ishizuka et al., 2016) and (4), i.e., additional emissions from the reactor buildings of FDNPP (TEPCO, 2012, 2013, 2014a, b, 2015), were considered in the present study. With respect to source (2), since the town of Namie is located in the evacuation zone, human activity has been extremely limited except for decontaminationrelated work. Although the decontamination-related work could be a potential source of re-suspension, it is not considered in the current simulation as the re-suspension flux has been hardly quantified. As to source (3), there is a low risk of forest fires in Japan given the high humidity, although some open biomass burning remains possible. Kinase et al. (2016) found no increase in ${ }^{137} \mathrm{Cs}$ activities when the concentration of levoglucosan, a marker of biomass burning, was increased, and thus re-suspension due to biomass burning was not considered in the present study. In addition to the four sources of ${ }^{137} \mathrm{Cs}$ from the Chernobyl accident, re-suspension from terrestrial biota was considered as suggested by Kinase et al. (2016). They found substantial amounts of bioaerosols upon scanning electron microscopy samples collected in the summer, when ${ }^{137} \mathrm{Cs}$ concentration was high.

In the present study, the long-term effect of radiocesium re-suspension from contaminated soil and terrestrial biota was quantitatively assessed using 3-D numerical simulation, a field experiment on dust emission flux in a contaminated area (Namie, Fukushima prefecture), and air concentration measurements conducted inside (Namie) and outside (city of Tsukuba, Ibaraki prefecture) the contaminated area. Even though the re-suspension mechanisms still remain unknown, by utilizing the observational data both inside and outside, together with the transport model, we aimed to provide as robust an analysis as possible of the re-suspension, transport, and re-deposition of ${ }^{137} \mathrm{Cs}$ over the Tohoku and Kanto regions of Japan. 


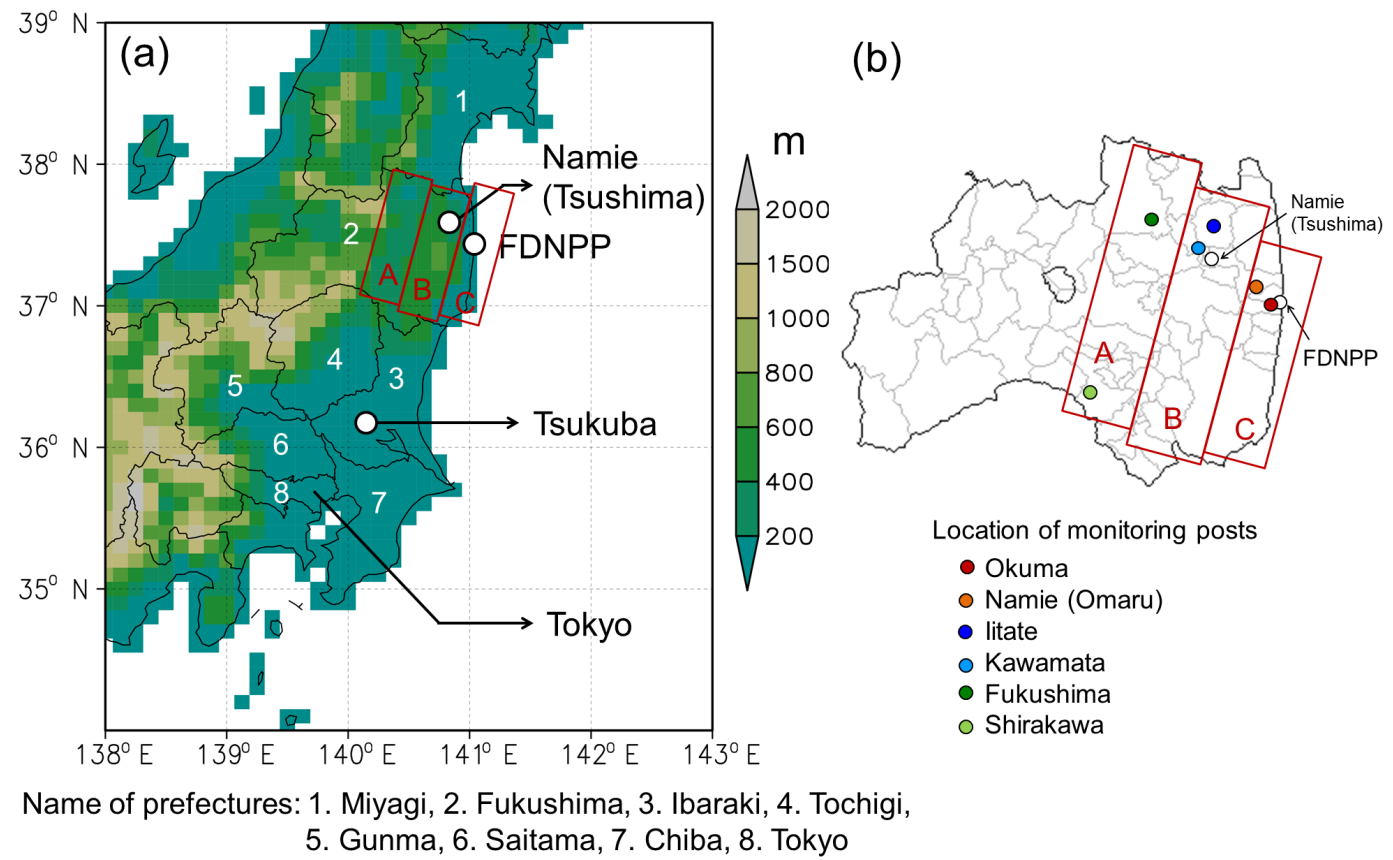

Figure 1. (a) The model domain showing the model terrestrial elevation, observation sites, and other locations described in the study. The linear distances from FDNPP to Namie (Tsushima district, town of Namie), Tsukuba and Tokyo are approximately 30, 170, and 220 km, respectively. The numbers denote prefectures: 1, Miyagi; 2, Fukushima; 3, Ibaraki; 4, Tochigi; 5, Gunma; 6, Saitama; 7, Chiba; and 8, Tokyo. (b) Fukushima prefecture and (colored circles) the locations (village, town, or city name) of monitoring posts used in this study (see Fig. 14). The red letters in both (a) and (b) denote the name of the area based on geographical features: A, Nakadori valley; B, Abukuma highland; and $\mathrm{C}$, Hamadori coastal area.

\section{Numerical simulation}

A brief description of the numerical method, such as the processes considered in the model and simulation settings, is presented in this section, and detailed model formulations are described in Appendix A. Because the schemes and assumptions regarding the emissions are key to the current study, they are described in detail in the following subsections.

\subsection{Lagrangian model and simulation settings}

Figure 1 shows the domain of the Lagrangian model (LM) with model terrestrial elevations, covering $138-143^{\circ} \mathrm{E}$ and $34-39^{\circ} \mathrm{N}$. The model domain covers the southern part of the Tohoku region (the northern mountainous part of the domain, including Yamagata, Miyagi, and Fukushima prefectures), and includes the FDNPP and highly polluted areas such as the habitation-restricted zone (HRZ; 20-50 $\mathrm{mSv} \mathrm{yr}^{-1}$ ) and difficult-to-return zone (DRZ; > $50 \mathrm{mSv} \mathrm{yr}^{-1}$; METI, 2012). It also covers the Kanto region (or Kanto Plain, the largest plain in Japan, approximately $120 \mathrm{~km} \times 120 \mathrm{~km}$ ), a highly populated region that includes low to moderately polluted areas such as Tokyo, Gunma, Tochigi, Ibaraki, Saitama, and Chiba prefectures.

The LM considers horizontal and vertical diffusion and advection, gravitational settling, dry and wet depositions, and radioactive decay. It uses simple parameterizations for dry and wet deposition schemes, and it can be driven by meteorological analysis datasets so that it does not require a meteorological model to predict detailed meteorological fields and variables. The model was designed to be easily handled and computationally efficient so that non-specialists of numerical simulations can conduct long-term assessments of atmospheric diffusion problems using their desktop or laptop computers. The LM was designed for rough budget estimates, as presented in the current study, or for sensitivity analyses using a large number of parameters (e.g., Groëll et al., 2014; Quérel et al., 2015; Girard et al., 2016), rather than for process-oriented analysis (e.g., Morino et al., 2013; Katata et al., 2015) or sensitivity analyses of the physical and chemical parameters of aerosols (Adachi et al., 2013). Details of each process and parameter are described in Appendix A. Statistical error of a Lagrangian simulation is inversely proportional to the square of the number of Lagrangian particles (LPs). The statistical accuracy of the current simulation setting is discussed in Appendix B.

The Grid Point Value-Mesoscale Model (GPV-MSM) of the Japan Meteorological Agency (JMA) was used for meteorological analysis to calculate the transport of LPs. It covers $120-150^{\circ} \mathrm{E}$ and $23-47^{\circ} \mathrm{N}$ and provides 3-hourly and 16 pressure levels of 3-D meteorological variables, from 1000 to $100 \mathrm{hPa}$, with a horizontal grid resolution of approximately 
Table 1. The observation sites and monitoring posts used to provide data for this study.

\begin{tabular}{lll}
\hline Name & Location & Description \\
\hline Observation sites & & \\
\hline $\begin{array}{lll}\text { Namie (Tsushima) } \\
\text { Tsukuba }\end{array}$ & $140.7683^{\circ} \mathrm{E}, 37.5621^{\circ} \mathrm{N}$ & Namie High School, Tsushima Campus ${ }^{1}$ \\
\hline Monitoring posts & & \\
\hline Okuma & $140.1254^{\circ} \mathrm{E}, 36.0551^{\circ} \mathrm{N}$ & Meteorological Research Institute \\
Namie (Omaru) & $140.9969^{\circ} \mathrm{E}, 37.4166^{\circ} \mathrm{N}$ & Ottozawa 3 Community Center $^{2}$ \\
Iitate & $140.7385^{\circ} \mathrm{E}, 37.6772^{\circ} \mathrm{N}$ & Iitate Junior High School $^{4}$ \\
Kawamata & $140.6979^{\circ} \mathrm{E}, 37.5836^{\circ} \mathrm{N}$ & Yamakiya Otsu 8 Community Firehouse $^{5}$ \\
Fukushima & $140.4765^{\circ} \mathrm{E}, 37.6870^{\circ} \mathrm{N}$ & Fukushima-Minami Fire Department \\
Shirakawa & $140.1904^{\circ} \mathrm{E}, 37.1241^{\circ} \mathrm{N}$ & Takayama-Kita Park $^{3}$ \\
\hline
\end{tabular}

${ }^{1}$ Original location (now moved to city of Nihonmatsu). ${ }^{2}$ Ottozawa San-ku Chiku Shukaijo (in Japanese). ${ }^{3}$ Omaru

Tamokuteki Shukaijo (in Japanese). ${ }^{4}$ Original location (now moved to city of Fukushima). ${ }^{5}$ Yamakiya Otsu Hachi-ku

Community Shoubou Center (in Japanese).

$11 \mathrm{~km}\left(\Delta\right.$ longitude $=0.125^{\circ}$ and $\Delta$ latitude $\left.=0.1^{\circ}\right)$ and surface variables at twice the resolution of that for the 3-D variables $\left(\Delta\right.$ longitude $=0.0625^{\circ}$ and $\Delta$ latitude $\left.=0.05^{\circ}\right)$. In the simulation, the whole model domain where LPs can travel is $138-143^{\circ} \mathrm{E}, 34-39^{\circ} \mathrm{N}$ and from ground surface to $500 \mathrm{hPa}$. For output of the model results, LP fields are converted to Eulerian concentration $\left(\mathrm{Bq} \mathrm{m}^{-3}\right)$ and deposition $\left(\mathrm{Bq} \mathrm{m}^{-2}\right)$ fields in the same horizontal space as the 3-D variables but are vertically allocated from the ground surface to an altitude of $1 \mathrm{~km}$ at $100 \mathrm{~m}$ intervals. The observed surface air concentration was compared with the simulated mean concentration at $0-100 \mathrm{~m}$ above ground level (AGL).

\subsection{Re-suspension from bare soil}

Ishizuka et al. (2016) developed a re-suspension scheme for radiocesium from bare soil based on measurements on the schoolyard at Namie High School, Tsushima Campus (denoted as Namie (Tsushima) in Table 1 and Fig. 1), in the DRZ.

$F_{\text {soil }}=p_{20 \mu \mathrm{m}} F_{\mathrm{M}}\left(1-f_{\text {forest }}\right) B_{5 \mathrm{~mm}}(t)$,

where $F_{\text {soil }}$ is the ${ }^{137} \mathrm{Cs}$ dust re-suspension flux from soil $\left(\mathrm{Bq} \mathrm{m}^{-2} \mathrm{~s}^{-1}\right), p_{20 \mu \mathrm{m}}$ is the surface area fraction of dust smaller than $20 \mu \mathrm{m}$ in diameter against soil containing a maximum size of $2 \mathrm{~mm}$ particles and varies depending on soil texture $\left(1.3 \times 10^{-8}\right.$ for sand, 0.19 for loamy sand, 0.45 for sandy loam, and 0.80 for silt loam), $F_{\mathrm{M}}$ is the total dust mass flux $\left(\mathrm{kg} \mathrm{m}^{-2} \mathrm{~s}^{-1}\right), f_{\text {forest }}$ is the forest area fraction, and $B_{5 \mathrm{~mm}}(t)$ is the specific radioactivity of surface soil (from the surface to a depth of $5 \mathrm{~mm} ; \mathrm{Bq} \mathrm{kg}^{-1}$ ) as a function of time since March 2011. The formula is based on the assumption that dust particles smaller than $20 \mu \mathrm{m}$ in diameter originating from the surface soil and to a depth of $5 \mathrm{~mm}$ were suspended and transported through the atmosphere. The surface area fraction was used for $p_{20 \mu m}$ based on the assumption that radiocesium is bound to the surface of soil particles (Evrard et al., 2015). $F_{\mathrm{M}}$ is formulated as being proportional to the cube of the friction velocity $u_{*}\left(\mathrm{~m} \mathrm{~s}^{-1}\right)$ as described by Loosmore and Hunt (2002) and was applied to the dust emission:

$F_{\mathrm{M}}=3.6 \times 10^{-9} u_{*}^{3}$.

Since $u_{*}$ is not available in GPV-MSM, $u_{*}$ was estimated using a wind speed at $10 \mathrm{~m}$ AGL by assuming neutral stratification conditions.

$B_{5 \mathrm{~mm}}(t)$ was derived from the combination of $B_{\mathrm{obs}}$, the observed horizontal distribution of ${ }^{137} \mathrm{Cs}$ deposition obtained from an airborne radiological survey (NRA, 2012; $\mathrm{Bq} \mathrm{m}^{-2}$ ), and $r_{5 \mathrm{~mm}}$, the surface soil activity ratio of $0-5 \mathrm{~mm}$ to $0-5 \mathrm{~cm}$ obtained from a vertical profile measurement of ${ }^{137} \mathrm{Cs}$ in the ground soil at Namie High School (i.e., $0.57 \mathrm{~Bq} \mathrm{~Bq}^{-1}$ ), as

$B_{5 \mathrm{~mm}}(t)=\frac{B_{\mathrm{obs}} r_{5 \mathrm{~mm}} R_{\text {decay }}(t)}{5 \times 10^{-3} \rho_{\mathrm{b}, \text { soil }}}$,

where $\rho_{\mathrm{b} \text {, soil }}$ is the bulk density of soil particles per unit volume in the ground space $\left(\mathrm{kg} \mathrm{m}^{-3}\right)$ obtained from the porosity $\left(0.4 \mathrm{~m}^{3} \mathrm{~m}^{-3}\right)$ and the density of dust particles $\left(2650 \mathrm{~kg} \mathrm{~m}^{-3}\right)$. For $R_{\text {decay }}$, which is the decreasing ratio of activity in the ground to its initial state $\left(R_{\text {decay }}(t=0)=1\right)$, only radioactive decay was considered for the re-suspension calculation. The decreasing rate due to other processes such as land surface processes (e.g., runoff, erosion, percolation and all the processes resulting in migration of radiocesium in the soil and biota; Evrard et al., 2015; Matsuda et al., 2015) and decontamination were not considered here. Furthermore, suppression of dust emission due to soil moisture and snow cover was not considered. Therefore, it should be noted here that $F_{\text {soil }}$ in Eq. (1) is considered as the upper boundary of ${ }^{137} \mathrm{Cs}$ re-suspension flux from surface soil. Effects such as land surface processes, decontamination, and dust emission suppression due to snow cover are extensively discussed in Sect. 5.3 

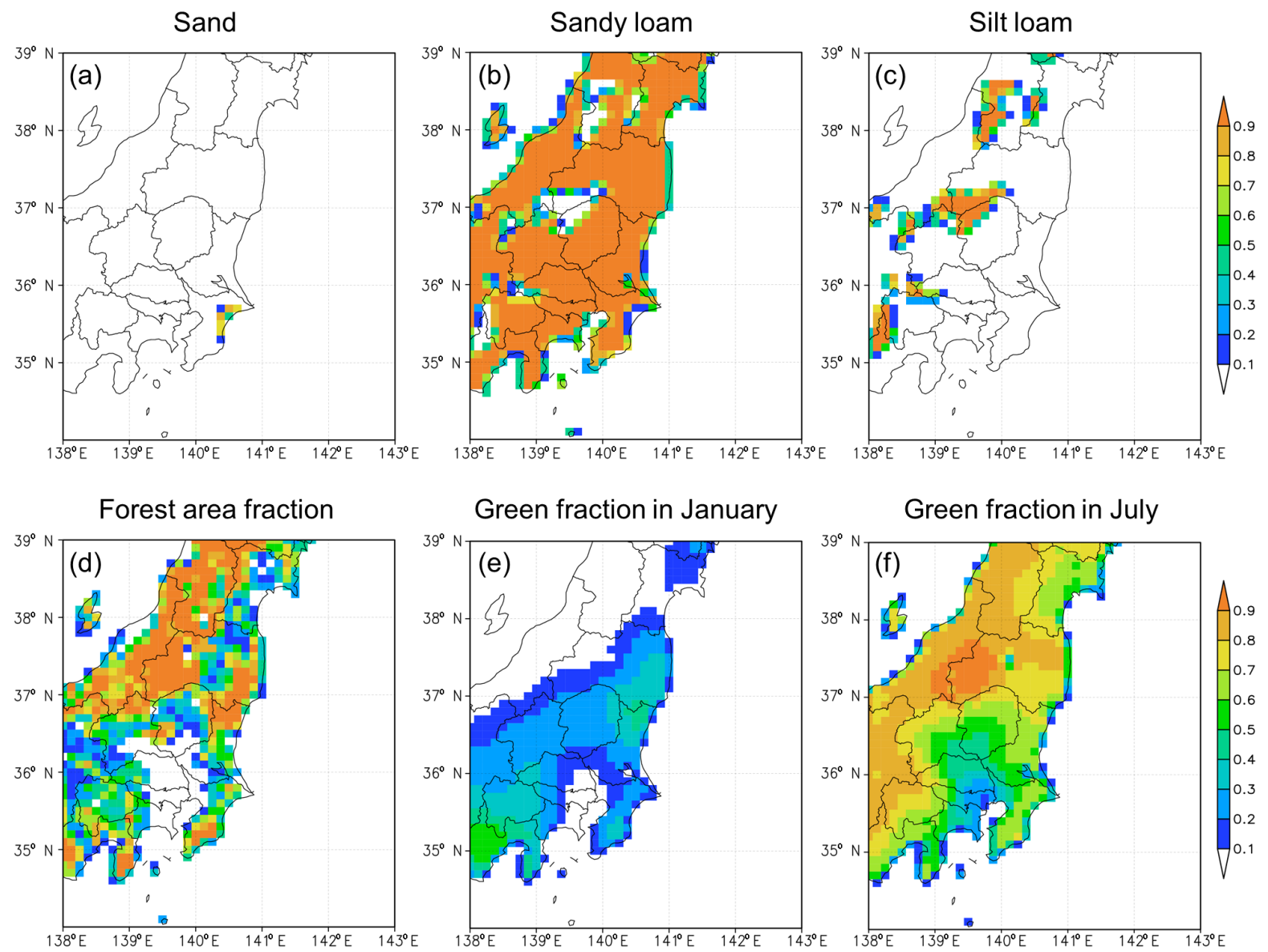

Figure 2. The areal fractions of (a)-(c) soil texture and (d)-(f) land use category used for the boundary conditions of the simulation.

using ambient gamma dose rate measurements obtained by the monitoring posts in Fukushima prefecture.

Equation (1) is a function of soil texture. The areal fraction of soil texture of the model grid was obtained from the database of the advanced research Weather Research and Forecasting model version 3 (WRFV3; Skamarock et al., 2008). Sixteen categories of soil texture (Miller and White, 1998) with a 30 arcsec resolution dataset can be obtained from the web after subscription at http://www2.mmm.ucar.edu/wrf/users/download/get_ sources_wps_geog.html and were re-categorized into the above-mentioned four categories (i.e., sand, loamy sand, sandy loam, and silt loam) and interpolated to the LM resolution $(\sim 11 \mathrm{~km})$ as shown in Fig. 2a-c. Note that the loamy sand fraction is not presented because it is zero for the entire domain. The parameter $f_{\text {forest }}$ (Fig. 2d) was also obtained from the database of WRFV3 and was calculated based on the 24 United States Geological Survey (USGS) land use categories, which are constant over time. The land use category dataset can also be obtained from the above website.

Ishizuka et al. (2016) validated their dust emission module by using a 1-D model and observed the surface air concen- tration of ${ }^{137} \mathrm{Cs}$ at Namie in the winter. After applying the module to our 3-D simulation, we found that the air concentration at Namie was underestimated by about factor of 5 for the same period. The module was formulated based on physical parameters (such as $u_{*}$ ) but contains parameters obtained at a single location (such as $r_{5 \mathrm{~mm}}$ and $\rho_{\mathrm{b} \text {, soil }}$ ) and under a fixed atmospheric condition (Ishizuka et al., 2016), whereas ideally parameters in Eqs. (1)-(3) should have considered variations among locations and atmospheric conditions for the 3-D simulation. We simply multiplied the dust emission flux by 5 after adjusting the simulation results against the observed concentration of ${ }^{137} \mathrm{Cs}$ at Namie in the winter. This is one of the simplest top-down approaches for adjusting the emission flux according to the air concentration. The module requires improvement in the future as more reliable parameters become available for various conditions and locations.

\subsection{Re-suspension from the forest ecosystems}

The re-suspension mechanism of radiocesium from land ecosystems remains unknown. Kinase et al. (2016) found substantial amounts of bioaerosols (rather than mineral dust 
particles) in samples collected for scanning electron microscopy in the summer, when the ${ }^{137} \mathrm{Cs}$ concentration was high. This does not prove that the bioaerosol was carrying radiocesium but that it could be a potential carrier. The behavior of $\mathrm{Cs}$ in the environment can be inferred by analogy with $\mathrm{K}$, a congener of Cs. Potassium is a necessary and abundant element in plants and circulates between land ecosystems. The addition of potassium fertilizer to a rice field in Fukushima significantly reduced the Cs content of the rice (Ohmori et al., 2014). Substantial amounts of Ksalt-rich particles, possibly emitted by active biota such as plants and fungi, and coated with secondary organic aerosols, were observed in pristine Amazonian rainforest (Pöhlker et al., 2012). The major areal fraction of the contaminated area in Fukushima is covered by biota-rich mountain forests. Despite the differences in plant species and locations, it is plausible that water-soluble radiocesium circulating in the biota and soil in the forests was somehow re-emitted into the atmosphere and contributed to the surface air concentration. The re-suspension from the forest ecosystem was simply formulated as follows:

$F_{\text {forest }}=f_{\text {forest }} f_{\text {green }} r_{\text {const }} B_{\text {obs }} R_{\text {decay }}(t)$,

where $F_{\text {forest }}$ is the ${ }^{137} \mathrm{Cs}$ re-suspension flux from forest $\left(\mathrm{Bq} \mathrm{m}^{-2} \mathrm{~s}^{-1}\right) ; f_{\text {forest }}$ is the forest area fraction; $f_{\text {green }}$ is the monthly green area fraction; $r_{\text {const }}$ is the constant re-suspension coefficient $\left(\mathrm{s}^{-1}\right)$; and, as in Eq. (3), $B_{\mathrm{obs}}$ and $R_{\text {decay }}$ are the observed ${ }^{137}$ Cs deposition (NRA, 2012; $\mathrm{Bq} \mathrm{m}^{-2}$ ) and the decreasing ratio of activity in the ground, respectively. $r_{\text {const }}$ is a tunable parameter to adjust the simulated air concentration of ${ }^{137} \mathrm{Cs}$ to that observed. In the current study, $r_{\text {const }}$ is set to $10^{-7} \mathrm{~h}^{-1}$ by adjusting the simulation data using the observed ${ }^{137} \mathrm{Cs}$ concentration at Namie in the summer, when the re-suspension from soil was negligible due to the higher soil moisture content (following considerable rain) and lower wind speed. As with re-suspension from bare soil, only radioactive decay was considered for $R_{\text {decay }}$ and the other processes were not considered. The parameter $f_{\text {green }}$ was obtained from the database of WRFV3 and was originally derived from satellite Advanced Very High Resolution Radiometer (AVHRR) normalized difference vegetation index (NDVI) data (Gutman and Ignatov, 1998). Whereas $f_{\text {forest }}$ remains constant, the monthly averaged $f_{\text {green }}$ was used in order to reflect seasonal changes in the activity of the biota.

\subsection{Emission from FDNPP (primary emission, additional emissions from the reactor buildings, and unexpected re-suspension associated with debris removal operations)}

The Japan Atomic Energy Agency (JAEA)'s latest estimate of the primary emission from FDNPP, Katata et al. (2015), was applied for the emergency situation of March 2011 to evaluate the performance of the LM model against the hori-

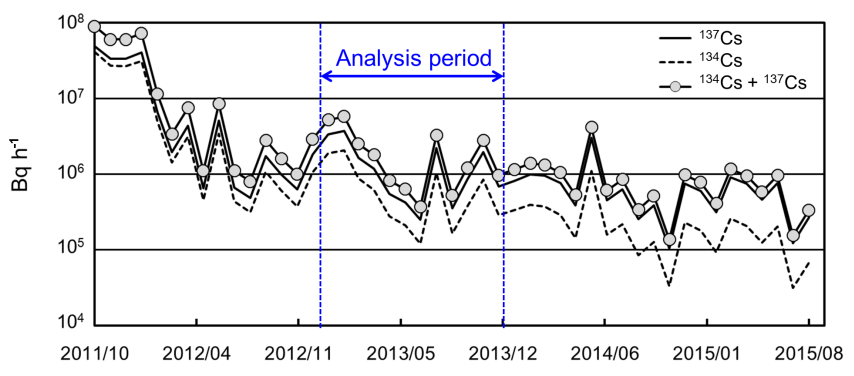

Figure 3. Monthly mean emission flux of radiocesium released from the reactor buildings of FDNPP from October 2011 to August 2015 as estimated by TEPCO (TEPCO, 2012-2015).

zontal distribution of ${ }^{137} \mathrm{Cs}$ deposition of the airborne radiological survey (NRA, 2012; as shown later in Fig. 4a) and surface air concentrations measured at Tsukuba (Fig. 1a). We selected this inventory because it is JAEA's most up-todate version. Based on an integrated understanding of environmental radioactivity, atmospheric dispersion, and the nuclear reactors, the JAEA team has carefully established a series of inventories for about 5 years, starting with Chino et al. (2011), followed by Katata et al. (2012a, b) and Terada et al. (2012), and finally the current inventory (Katata et al., 2015), which is substantially improved compared to the previous versions.

Ongoing emissions during the study analysis period after the emergency situation, i.e., January to December 2013, were obtained from the Tokyo Electric Power Co. Inc. (TEPCO) monthly mean emission flux from the reactor buildings (TEPCO, 2012, 2013, 2014a, b, 2015). Because only the sum of ${ }^{134} \mathrm{Cs}$ and ${ }^{137} \mathrm{Cs}$ was provided, the fractions of these two isotopes were calculated based on their halflives and the assumption that their activities were equal in March 2011 (e.g., Katata et al., 2015), as shown in Fig. 3. The values range from $10^{5}$ to $10^{7} \mathrm{~Bq} \mathrm{~h}^{-1}$; however, for simplicity we set a constant value of $10^{6} \mathrm{~Bq} \mathrm{~h}^{-1}$ in the current simulation.

In August 2013, unexpected re-suspension associated with debris removal operations was reported by TEPCO (2014c) and NRA (2014) and the gross amount was $10^{10}-10^{11} \mathrm{~Bq}$ of ${ }^{137}$ Cs (TEPCO, 2014c; NRA, 2014; Steinhauser et al., 2015). The impact of this unexpected re-suspension is briefly discussed in Sect. 5.2 along with an additional finding, but this emission was not considered in the present LM simulation. In this study we focused on the ongoing and continuous emission, mostly from the natural environment, that is difficult to control.

\section{Field observations}

Details of the surface air activity concentration measurement techniques can be found in Ishizuka et al. (2016) and $\mathrm{Ki}$ nase et al. (2016) for Namie and Igarashi et al. (2015) for 
Tsukuba. At the both sites, ${ }^{134} \mathrm{Cs}$ and ${ }^{137} \mathrm{Cs}$ surface air concentrations were measured. The sampling intervals were 12 days at Namie and 1 week at Tsukuba for the analysis period of this study, the year 2013. The observations at Namie started on 14 December 2012, while those at Tsukuba started on 31 March 2003, before the FDNPP accident. In March 2011, the sampling interval was increased at Tsukuba to $6 \mathrm{~h}-$ 1 day and the data for these periods were used for the validation of LM and its parameters, as presented in Sect. 4.1.

The Namie site is located on the schoolyard of Namie High School, Tsushima Campus, in the Tsushima district of Namie in Fukushima prefecture, as shown in Table 1 and Fig. 1. The town of Namie extends from the Hamadori coastal area (denoted as $\mathrm{C}$ in Fig. 1) to the Abukuma highland area (B in Fig. 1). There are two sites in Namie used in the study. In order to distinguish the Tsushima Campus site in the highland area from the monitoring post site located in Omaru district in Namie in the coastal area, the Tsushima site is referred to as Namie (sometimes as Namie (Tsushima)) and the Omaru site is referred to as Omaru (sometimes as Namie (Omaru)) throughout the manuscript. The Tsukuba site is located on the premises of the Meteorological Research Institute (Table 1 and Fig. 1a).

Namie (Tsushima) was located in the DRZ $\left(>50 \mathrm{mSv} \mathrm{yr}^{-1}, \sim 9.55 \mu \mathrm{Sv} \mathrm{h}^{-1}\right.$ ) and the observed ${ }^{137} \mathrm{Cs}$ deposition amount was $2300 \mathrm{kBq} \mathrm{m}^{-2}$ (NRA, 2012). The ambient gamma dose rate was $11.2 \mu \mathrm{Svh}^{-1}$ on 1 April 2012 at the site and had dropped to $4.8 \mu \mathrm{Sv} \mathrm{h}^{-1}$ on 16 February 2016 and at the HRZ level $\left(20-50 \mathrm{mSv} \mathrm{yr}^{-1}\right.$, $\left.3.85-9.55 \mu \mathrm{Sv} \mathrm{h}^{-1}\right)$. Tsukuba is located approximately $170 \mathrm{~km}$ southwest of FDNPP. The observed ${ }^{137} \mathrm{Cs}$ deposition amount was $21 \mathrm{kBq} \mathrm{m}^{-2}$ (NRA, 2012), 2 orders of magnitude lower than at Namie, and the dose rate has remained below $0.1 \mu \mathrm{Sv} \mathrm{h}^{-1}$ since 2012 .

\section{Results}

Section 4.1 presents a validation of the LM model and the optimization of the model deposition parameters by using airborne observations (NRA, 2012) and the emission inventory of Katata et al. (2015) for the emergency situation of March 2011. Using the optimized ranges of model parameters validated in Sect. 4.1, the simulated re-suspension of ${ }^{137} \mathrm{Cs}$ from soil and forest, as well as emission from FDNPP, is presented in Sect. 4.2, and the budgets for re-suspension, transport, and re-deposition are presented in Sect. 4.3.

\footnotetext{
${ }^{1}$ Calculated by the following equation: Annual radiation exposure $=($ ambient dose rate - background dose rate $\left.\left(=0.04 \mu \mathrm{Svh}^{-1}\right)\right) \times(8 \mathrm{~h}+0.4 \times 16 \mathrm{~h}) \times 365$ days.
}

\subsection{Model and parameter validation for the emergency situation (March 2011)}

Figures 4 and 5 show the observed and simulated distribution of ${ }^{137}$ Cs deposition in March 2011, and the scatterplot comparing the observational and simulation results. In the simulation shown in the figures, the "reference" sets used for dry and wet deposition parameters, namely the collection efficiency of aerosols using hydrometeors $E_{\mathrm{c}}(\mathrm{Eq}$. A1) and the dry deposition velocity over land $v_{\mathrm{d}}$ (Eq. A3), were 0.04 and $0.1 \mathrm{~cm} \mathrm{~s}^{-1}$, respectively.

Since LM uses simple parameterizations for dry and wet deposition, as described in Appendix A, sensitivity tests were conducted for model validation, together with optimization of the deposition parameters. Table 2 summarizes the ranges of the deposition parameters for the sensitivity tests and the results of the ${ }^{137} \mathrm{Cs}$ budget and statistical measurements between the observations and the simulation.

The parameter $E_{\mathrm{c}}$ was 0.05 for the JMA dispersion model (JMA, 1998) but the targeted species are different. For example, volcanic ash (particles larger than $1 \mu \mathrm{m}$ in diameter) used for the JMA model was generally larger than the aerosols carrying ${ }^{137} \mathrm{Cs}$ (around $1 \mu \mathrm{m}$ in diameter observed in the downwind area, Tsukuba; Kaneyasu et al., 2012; Adachi et al., 2013). Since the inertia of these smaller ${ }^{137} \mathrm{Cs}$ particles is likely to be smaller than that for volcanic ash, $E_{\mathrm{c}}$ could be smaller. The range of $E_{\mathrm{c}}$ was set as $0.02-0.06$. The dry deposition velocity $v_{\mathrm{d}}$ was selected as $0.1 \mathrm{~cm} \mathrm{~s}^{-1}$ for ${ }^{137} \mathrm{Cs}$ in Furuno et al. (1999). The range for $v_{\mathrm{d}}$ was set as 0.05 to 0.15 in the present study.

The emission inventory of Katata et al. (2015) amounted to $14.1 \mathrm{PBq}$ from 12 March to 1 April 2013. The simulated deposition over the model domain $\left(138-143^{\circ} \mathrm{E}, 34-39^{\circ} \mathrm{N}\right)$ ranged from 3.4 to $4.7 \mathrm{PBq}$, which is approximately $24-33 \%$ of the emission from the FDNPP. Sixty percent of the total deposition occurred over land, for a total of $2.0-2.8 \mathrm{PBq}$, which is close to the observed value of $2.68 \mathrm{PBq}$, and the observed value is within the range of the sensitivity runs. Statistical measures such as the fractional bias FB, the correlation coefficient $R$ (linear vs. linear), and FAx (fraction of the simulated values within a factor of $x$ ) are listed in Table 2 . To find better combinations of (or to optimize) the dry and wet deposition parameters, sensitivity runs were screened based on the criteria FA10 $>0.9$, FA5 $>0.7, R>0.75$, and an absolute value of $\mathrm{FB}<10 \%$. Only one combination $\left(E_{\mathrm{c}}\right.$, $\left.v_{\mathrm{d}}\right)=\left(0.04,0.1 \mathrm{~cm} \mathrm{~s}^{-1}\right)$ satisfied the criteria, and thus this is referred to as the "reference" parameters. To evaluate the sensitivity (or uncertainty) of the re-suspension simulation for 2013 due to the deposition parameters, the range of the combination of parameters was set as $\left(E_{\mathrm{c}}, v_{\mathrm{d}}\right)=(0.03-$ $0.05,0.05-0.1 \mathrm{~cm} \mathrm{~s}^{-1}$ ) around the reference parameters (referred to as the "optimized range") by excluding the parameters with the worse performances. The ranges of the statistical measures of the optimized runs are listed in Table 2. $\mathrm{FB}, R, \mathrm{FA} 2$, FA5, and FA10 after the optimization had the 
Table 2. ${ }^{137} \mathrm{Cs}$ budget and statistical analysis for the comparison of observed and simulated deposition data for March 2011.

\begin{tabular}{|c|c|c|c|c|c|c|c|c|}
\hline & $\begin{array}{l}E_{\mathrm{c}}^{\mathrm{a}} \\
(-)\end{array}$ & $\begin{array}{r}v_{\mathrm{d}}^{\mathrm{b}} \\
\left(\mathrm{cm} \mathrm{s}^{-1}\right)\end{array}$ & $\begin{array}{r}D_{\text {all }}^{\mathrm{c}} \\
(\mathrm{PBq})\end{array}$ & $\begin{array}{l}D_{\text {land }}^{\mathrm{d}} \\
(\mathrm{PBq})\end{array}$ & $\begin{array}{r}\mathrm{FB}^{\mathrm{e}} \\
(-)\end{array}$ & $\begin{array}{l}R^{\mathrm{f}} \\
(-)\end{array}$ & $\begin{array}{r}\mathrm{FA} 2^{\mathrm{g}} \\
(-)\end{array}$ & $\begin{array}{r}\mathrm{FA}^{\mathrm{h}} \\
(-)\end{array}$ \\
\hline \multicolumn{9}{|l|}{ Sensitivity test } \\
\hline Range & $0.02-0.06$ & $0.05-0.15$ & $3.4-4.7$ & $2.0-2.8$ & $\begin{array}{l}-0.25- \\
0.00050\end{array}$ & $0.73-0.78$ & $0.25-0.30$ & $0.63-0.77$ \\
\hline \multicolumn{9}{|l|}{$\begin{array}{l}\text { Optimization used for the } \\
\text { re-suspension analysis for } 2013\end{array}$} \\
\hline $\begin{array}{l}\text { Reference } \\
\text { Optimized range }\end{array}$ & $\begin{array}{r}0.04 \\
0.03-0.05\end{array}$ & $\begin{array}{r}0.10 \\
0.05-0.10\end{array}$ & $\begin{array}{r}4.2 \\
3.7-4.3\end{array}$ & $\begin{array}{r}2.5 \\
2.2-2.6\end{array}$ & $\begin{array}{r}-0.062 \\
-0.18 \text { to } \\
-0.036\end{array}$ & $\begin{array}{r}0.75 \\
0.74-0.77\end{array}$ & $\begin{array}{r}0.28 \\
0.26-0.30\end{array}$ & $\begin{array}{r}0.74 \\
0.68-0.74\end{array}$ \\
\hline \multicolumn{9}{|l|}{ Reference values } \\
\hline $\begin{array}{l}\text { Observed deposition over land } \\
D_{\text {obs }} \text { (NRA, 2012) } \\
\text { Emission amount } \\
\text { (Katata et al., 2015) }\end{array}$ & $\begin{array}{l}2.68 \mathrm{PBq} \\
14.1 \mathrm{PBq}\end{array}$ & & & & & & & \\
\hline
\end{tabular}

${ }^{\text {a }}$ Collection efficiency; see Eq. (A1) ${ }^{\mathrm{b}}$ Dry deposition velocity over land; see Eq. (A3). ${ }^{\mathrm{c}}$ Simulated deposited amount over the whole model domain. ${ }^{\mathrm{d}}$ Simulated deposited amount only over land. ${ }^{\mathrm{e}}$ Fractional bias between $D_{\text {land }}$ and $D_{\mathrm{obs}} \cdot{ }^{\mathrm{f}}$ Correlation coefficient between each grid cell of the observed and simulated deposition (linear vs. linear). ${ }^{g}$ Fraction of simulated values within a factor of 2 of the observed values. ${ }^{\mathrm{h}}$ Fraction of simulated values within a factor of 5 of the observed values. ${ }^{\mathrm{f}, \mathrm{g}, \mathrm{h}}$ Compared only at grids where the observed values are greater than $10 \mathrm{kBq} \mathrm{m}^{-2}$.
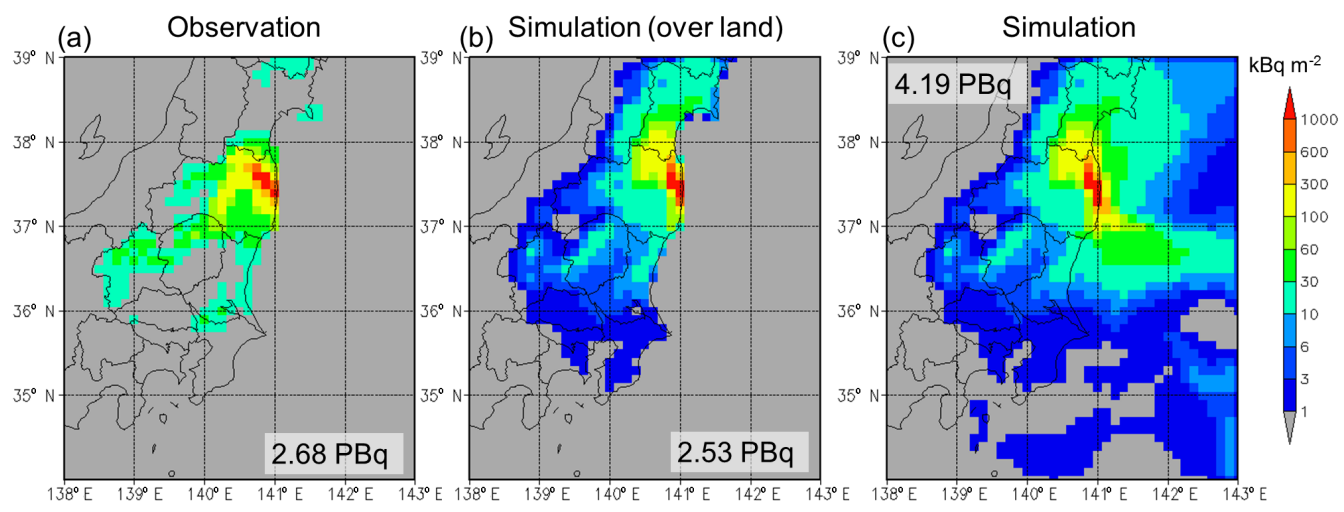

Figure 4. (a) Aircraft observation and (b, c) simulation of ${ }^{137} \mathrm{Cs}$ deposition depicted (b) only over land and (c) for the whole domain $\left(\mathrm{kBq} \mathrm{m}^{-2}\right)$. The observation was interpolated to the model grid $\left(\Delta\right.$ longitude $=0.125^{\circ}$ and $\Delta$ latitude $\left.=0.1^{\circ}\right)$. A decay correction for the observation was made for March-May 2012, varying depending on the region. The simulation provided a cumulative value from 12 March to 1 April 2011. The total activities are presented as numbers. The color scales are the same for (a)-(c) but observed values are not depicted below the detection limit, $10 \mathrm{kBq} \mathrm{m}^{-2}$. The deposition parameters of the simulation in the figure are $E_{\mathrm{c}}=0.04$ and $v_{\mathrm{d}}=0.1 \mathrm{~cm} \mathrm{~s}$.

ranges -0.18 to $-0.036,0.74-0.77,0.26-0.30,0.68-0.74$, and $0.91-0.92$, respectively. These statistical measures were comparable to those reported in previous multi-model comparison studies $(R$ : $0.27-0.85$; FB: $-0.84-0.56$; and FA2: 0.14-0.57, in SCJ, 2014; Draxler et al., 2015). The current model is thus shown to be sufficiently credible for the budget analysis in this study, despite the simple parameterization and the low resolution in space $(\sim 11 \mathrm{~km})$ and time $(3 \mathrm{~h})$.

In agreement with many previous studies, the simulated contribution of wet deposition was larger than that of dry deposition: the ratio of the amount of dry to wet deposition ranged from 0.12 to 0.23 for the optimized parameter ranges, indicating that the results were less sensitive to the dry deposition parameter. Generally speaking, $R$ became higher as $E_{\mathrm{c}}$ became lower, whereas FA $x$ became higher as $E_{\mathrm{c}}$ became higher for the various ranges of the sensitivity tests. Therefore, lower $E_{\mathrm{c}}$ did not meet the criteria of FAx and higher $E_{\mathrm{c}}$ did not meet the criteria of $R$. Consequently, after the optimization, the maximum values of the statistical measures were lower but the minimum values became higher, indicating that the optimization was successful in excluding the parameters with the worse performances (rather than selecting 


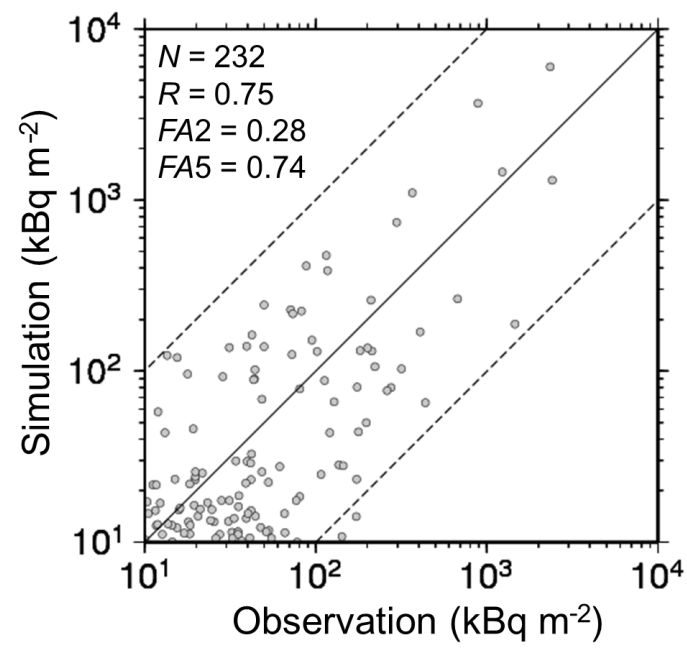

Figure 5. Scatterplot between the observational data and the simulation results for ${ }^{137} \mathrm{Cs}$ deposition $\left(\mathrm{kBqm}^{-2}\right)$. The deposition parameters of the simulation in the figure are $E_{\mathrm{c}}=0.04$ and $v_{\mathrm{d}}=0.1 \mathrm{~cm} \mathrm{~s}^{-1} . N$ indicates the number of samples, and the statistical measures $R$, FA2, and FA5 are described in Table 2.

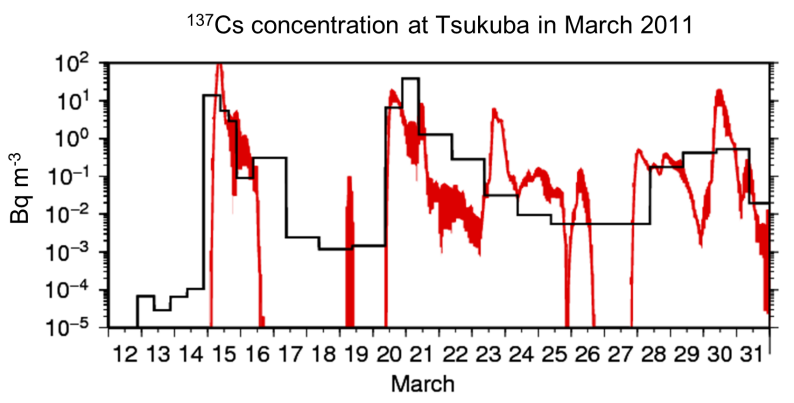

Figure 6. Time series of the surface activity concentration of (black) observed and (red) simulated ${ }^{137} \mathrm{Cs}$ concentrations at Tsukuba from 12 March to 1 April $2011\left(\mathrm{~Bq} \mathrm{~m}^{-3}\right)$. The red shaded areas indicate the range of ${ }^{137} \mathrm{Cs}$ concentrations obtained when the simulations were run using the optimized parameter ranges $E_{\mathrm{c}}=0.03-0.05$ and $v_{\mathrm{d}}=0.05-0.1 \mathrm{~cm} \mathrm{~s}^{-1}$.

the best parameters). It should be noted here that the optimized deposition parameters are not necessarily physically valid but rather give simulation results consistent with the available observations. The results presented in this section indicate that the current LM simulation with these optimized parameters has the potential to reproduce consistent features of the radiocesium budget over the Tohoku and Kanto regions of Japan.

Figure 6 shows the temporal variation in simulated (red) and observed (black) ${ }^{137} \mathrm{Cs}$ concentrations at Tsukuba in March 2011. The model reproduced the three major plumes arriving at Tsukuba on 15-16, 20-21, and 28-30 March; a plume on 23 March was not observed but only appeared in the simulation. The red shaded areas indicate the range of ${ }^{137} \mathrm{Cs}$ concentrations obtained when the simulations were run using the optimized parameter ranges $E_{\mathrm{c}}=0.03-0.05$ and $v_{\mathrm{d}}=0.05-0.1 \mathrm{~cm} \mathrm{~s}^{-1}$. Due to differences in the parameters used, the surface air concentration could vary by approximately 1 order of magnitude in transported plumes that experienced wet scavenging along their pathway.

\subsection{Re-suspension in 2013}

Figure 7 shows the observed and daily mean simulated (with the reference parameters) surface air concentrations at Namie and Tsukuba for the year 2013. The red, green, and blue lines indicate re-suspension from soil, re-suspension from forest, and emission from the FDNPP reactor buildings, respectively. Scatterplots between the observed and the simulated total concentrations are also shown in the figure and the statistical measures between them are listed in Table 3. The correlation coefficients (linear vs. linear) are low at the both sites, but the simulated and the observed medians are close to each other and FAx shows high values at the both sites. Consequently, the current simulation is credible enough for the quantitative assessment of the annual radiocesium budget.

As discussed in Sect. 2.2, note that the re-suspension flux due to the dust emission module (Ishizuka et al., 2016) is multiplied by 5 in this study in order to adjust to the observation level at Namie in the cold season (January to March, October to December). Also note that the re-suspension coefficient $r_{\text {const }}$ in Eq. (4) was set as $10^{-7} \mathrm{~h}^{-1}$ in order to adjust to the observation level at Namie in the warm season (May to September). The emission flux reported by TEPCO varied from $10^{5}$ to $10^{7} \mathrm{~Bq} \mathrm{~h}^{-1}$ during the study period but we set it to $10^{6} \mathrm{Bqh}^{-1}$ for simplicity. We did not try to precisely adjust $r_{\text {const }}$ to the observation by, for example, using inverse modeling, and instead we simply multiplied by power-of-10 values (except for dust emission, which is five), which are constant in time and space because (1) this facilitated straightforward interpretation of the simulation results by keeping the simulated variation solely originating from the variation in boundary conditions (i.e., emission and meteorology), and therefore (2) this provided simple but useful clues for understanding the re-suspension mechanisms, which remain unknown.

Using the dust emission module (which has a physical basis), ${ }^{137} \mathrm{Cs}$ flux re-suspended from soil could account for the level of the observed surface air concentration of ${ }^{137} \mathrm{Cs}$ at Namie in the cold season. Under the influence of the northwesterly winter monsoon, the surface wind speed is high over the contaminated area compared to the summer (as shown later in Fig. 10). Note that the flux might be a maximum estimate since it does not consider land surface processes (such as soil moisture, snow cover, or migration of ${ }^{137} \mathrm{Cs}$ in the soil and biota) and decontamination, which could reduce the ${ }^{137} \mathrm{Cs}$ re-suspension flux. In contrast, in the warm season, the estimated flux significantly underestimated the observation by 1 to 2 orders of magnitude due to the weak surface wind, indicating that the dust emission 
Table 3. Statistical analysis for the comparison of observed and simulated ${ }^{137}$ Cs air concentration at Namie and Tsukuba for 2013.

\begin{tabular}{lrrrrrrr}
\hline Site & $\begin{array}{r}N \\
(-)\end{array}$ & $\begin{array}{r}\text { Median, obs. } \\
\left(\mathrm{mBq} \mathrm{m}^{-3}\right)\end{array}$ & $\begin{array}{r}\text { Median, sim. } \\
\left(\mathrm{mBq} \mathrm{m}^{-3}\right)\end{array}$ & $\begin{array}{r}R \\
(-)\end{array}$ & $\begin{array}{r}\text { FA2 } \\
(-)\end{array}$ & $\begin{array}{r}\text { FA5 } \\
(-)\end{array}$ & $\begin{array}{r}\text { FA10 } \\
(-)\end{array}$ \\
\hline Namie & 311 & 0.71 & 0.69 & 0.12 & 0.67 & 0.94 & 0.99 \\
Tsukuba & 74 & 0.022 & 0.024 & 0.19 & 0.70 & 0.95 & 1.00 \\
\hline
\end{tabular}

(a)

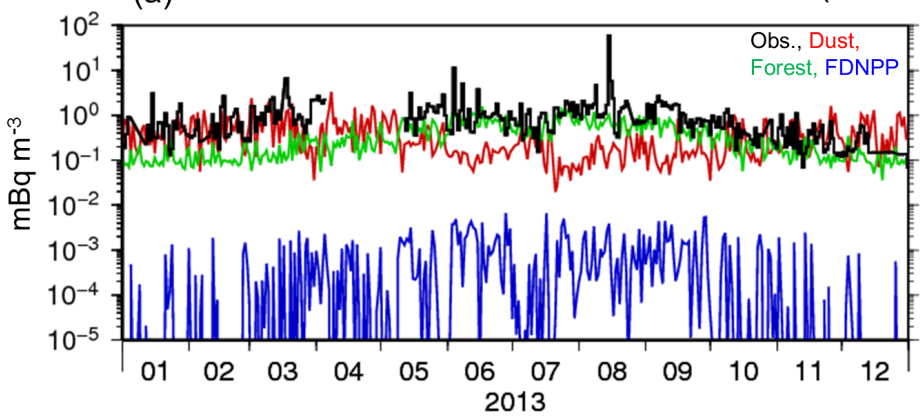

(b)

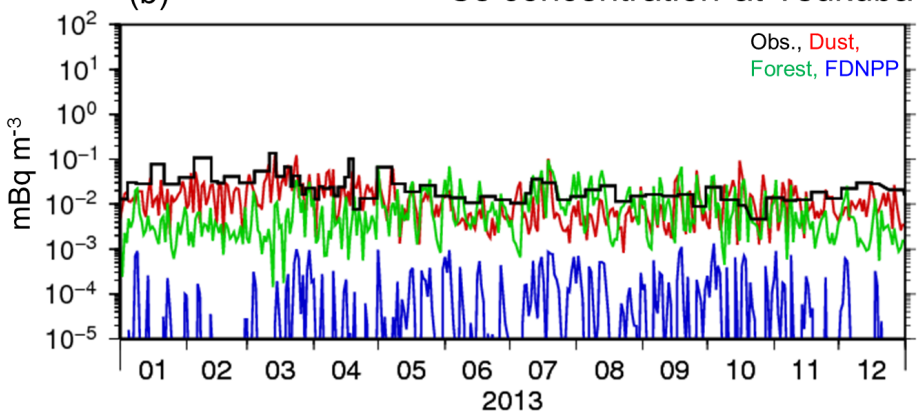

${ }^{137} \mathrm{Cs}$ concentration at Tsukuba in 2013

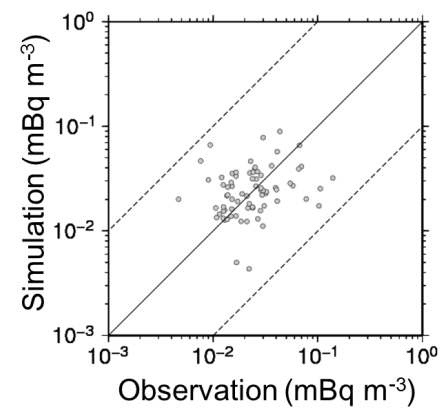

Figure 7. Time series of the surface air concentration of (black) observed ${ }^{137} \mathrm{Cs}$ and (colors) simulated daily ${ }^{137} \mathrm{Cs}$ levels on the left and scatterplots between observed and simulated total (i.e., sum of colors) ${ }^{137} \mathrm{Cs}$ at (a) Namie and (b) Tsukuba. The colored lines indicate simulated ${ }^{137} \mathrm{Cs}$ concentrations due to (red) re-suspension from soil using the scheme given in Ishizuka et al. (2016) (five times), (green) re-suspension from forest with a re-suspension rate of $10^{-7} \mathrm{~h}^{-1}$, and (blue) emission from the FDNPP reactor buildings with a constant emission rate of $10^{6} \mathrm{Bqh}^{-1}$. The deposition parameters of the simulation in the figure are $E_{\mathrm{c}}=0.04$ and $v_{\mathrm{d}}=0.1 \mathrm{~cm} \mathrm{~s}$.

process may not be the sole process involved in sustaining the air concentration of ${ }^{137} \mathrm{Cs}$ during this period. Introducing the ${ }^{137} \mathrm{Cs}$ re-suspension component from forest with a resuspension coefficient of $10^{-7} \mathrm{~h}^{-1}$ and a monthly variation in the green area fraction (derived from NDVI) could quantitatively account for the observed air concentration together with its seasonal variation at Namie. Even though both the simulated re-suspension from soil and forests reproduced the quantity and seasonal variation in the background concentration (in other words, concentrations originating from continuously presenting emissions, such as natural emissions, and not accidental ones) at Namie, sporadic peak events, such as the daily mean ${ }^{137} \mathrm{Cs}$ concentration exceeding $10 \mathrm{mBq} \mathrm{m}^{-3}$ as observed in June and August at Namie, were not simulated. Some specific re-suspension events might occur from the highly contaminated areas such as the premises of FD-
NPP (e.g., debris removal operations) or very close to FDNPP on these days, as indicated later in Sect. 5.2. The simulated ${ }^{137} \mathrm{Cs}$ concentrations due to the monthly mean emission from the reactor buildings (i.e., $10^{6} \mathrm{~Bq} \mathrm{~h}^{-1}$ ) significantly underestimated the observed concentration by more than 3 orders of magnitude at Namie and by 2 orders of magnitude at Tsukuba. Even the maximum estimate of $10^{7} \mathrm{~Bq} \mathrm{~h}^{-1}$ does not reach the observed level. The emission from FDNPP may not have been the sole process sustaining the air concentration of ${ }^{137} \mathrm{Cs}$ in 2013, supporting the discussion in Igarashi et al. (2015), which concluded that direct emission from the FDNPP played a minor role in the observed atmospheric radiocesium concentrations over Tsukuba during 2013-2014.

The observed air concentration of ${ }^{137} \mathrm{Cs}$ at Tsukuba was about 1 to 2 orders of magnitude lower than that at Namie. The simulated difference between the two sites inside and 
(a) Annual re-suspension of ${ }^{137} \mathrm{Cs}\left(\mathrm{Bq} \mathrm{m}^{-2}\right)$

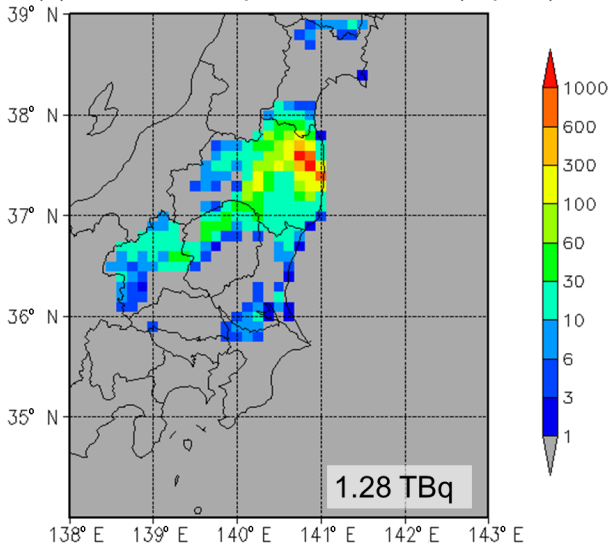

(c) Fraction of re-suspension to deposition of ${ }^{137} \mathrm{Cs}(\%)$

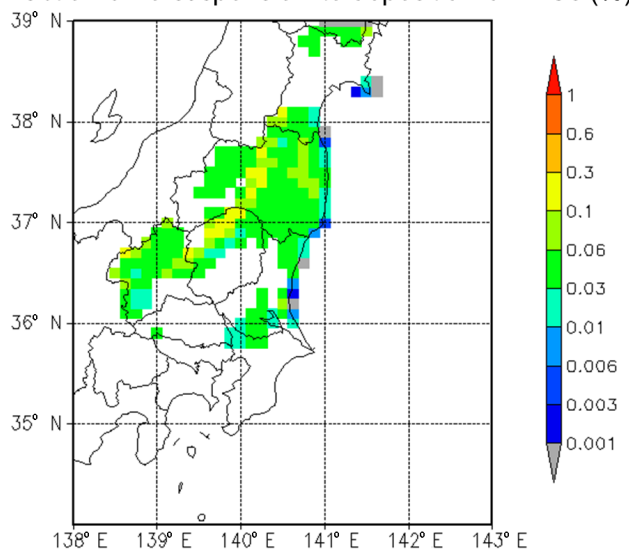

(b) Annual re-deposition of ${ }^{137} \mathrm{Cs}\left(\mathrm{Bq} \mathrm{m}^{-2}\right)$

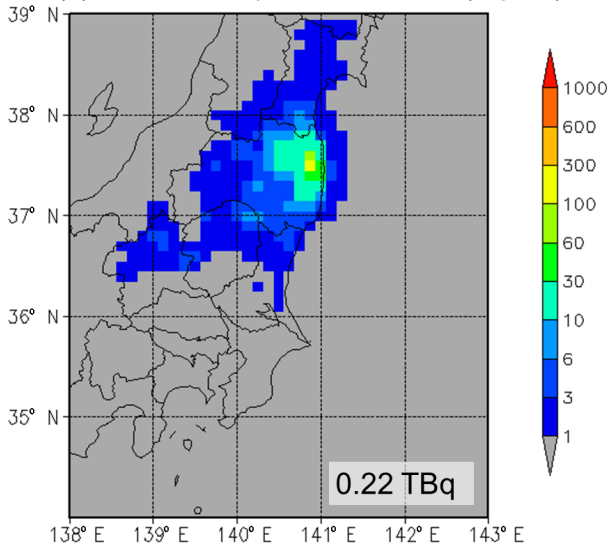

(d) Fraction of re-deposition to deposition of ${ }^{137} \mathrm{Cs}(\%)$

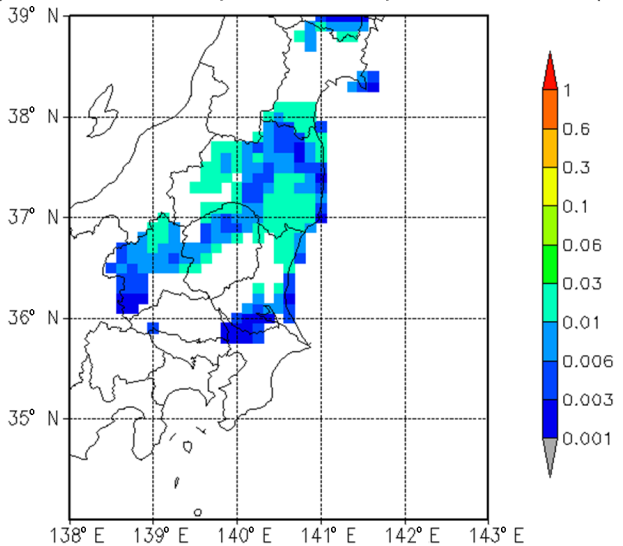

Figure 8. Annual total amounts of (a) the re-suspension and (b) the re-deposition of ${ }^{137} \mathrm{Cs}$. The total activities are presented as numbers. Fractions of the re-suspension and the re-deposition to the observed ${ }^{137} \mathrm{Cs}$ deposited amounts are also shown in (c) and (d), respectively. The deposition parameters of the simulation in the figure are $E_{\mathrm{c}}=0.04$ and $v_{\mathrm{d}}=0.1 \mathrm{~cm} \mathrm{~s}^{-1}$.

outside of the contaminated areas was consistent with the observed difference. This finding indicates that the current LM simulation provided consistent features of re-suspension, transport, and re-deposition in the Tohoku and Kanto regions of Japan of ${ }^{137} \mathrm{Cs}$ originating from Fukushima.

\subsection{Budget analysis}

Figure 8 illustrates the simulated (with the reference parameters) annual amounts of total re-suspension and re-deposition of ${ }^{137} \mathrm{Cs}$, together with their ratios to the observed deposition (Fig. 4a). The simulated areal total re-suspended amount was $1.28 \mathrm{TBq}$, which was equivalent to $0.048 \%$ of the total deposited amount, $2.68 \mathrm{PBq}$. The areal total re-deposited amount (with the reference parameters) was $0.22 \mathrm{TBq}(0.18$ $0.23 \mathrm{TBq}$ for the optimized range of the deposition parameters), corresponding to approximately 17.2 (14.1-18.0) \% of the re-suspended amount deposited mainly in the Tohoku region, with the remainder being transported out of the model domain. Therefore, the regional mean rate in the decrease of the land surface ${ }^{137} \mathrm{Cs}$ concentration due to re-suspension was estimated to be $0.040(0.039-0.041) \% \mathrm{yr}^{-12}$, equivalent to $1.1(1.06-1.12) \times 10^{-6} \mathrm{day}^{-1}$. The spatial distribution of the re-suspension and re-deposition ratio to the primary deposition ranged from 0.01 to 0.3 and 0.001 to $0.03 \%$, respectively. The spatial distribution of the land surface ${ }^{137} \mathrm{Cs}$ deposition decay due to re-suspension ranged from $2.7 \times 10^{-7}$ to $8.2 \times 10^{-6} \mathrm{day}^{-1}$. Re-suspension therefore had a negligible effect on reducing land surface radioactive contamination.

\section{Discussion}

Seasonal variation in the surface activity concentration and its source contributions are extensively discussed in Sect. 5.1. A possible source of the observed sporadic peak events, which could not be reproduced by the simulation, is dis-

\footnotetext{
${ }^{2}$ The amount re-suspended, excluding re-deposition $(1.28 \mathrm{TBq}$ minus $0.22(0.18-0.23) \mathrm{TBq})$ for the year 2013, divided by the total deposited amount of $2.68 \mathrm{PBq}$.
} 
${ }^{137} \mathrm{Cs}$ concentration at Namie (Tsushima)
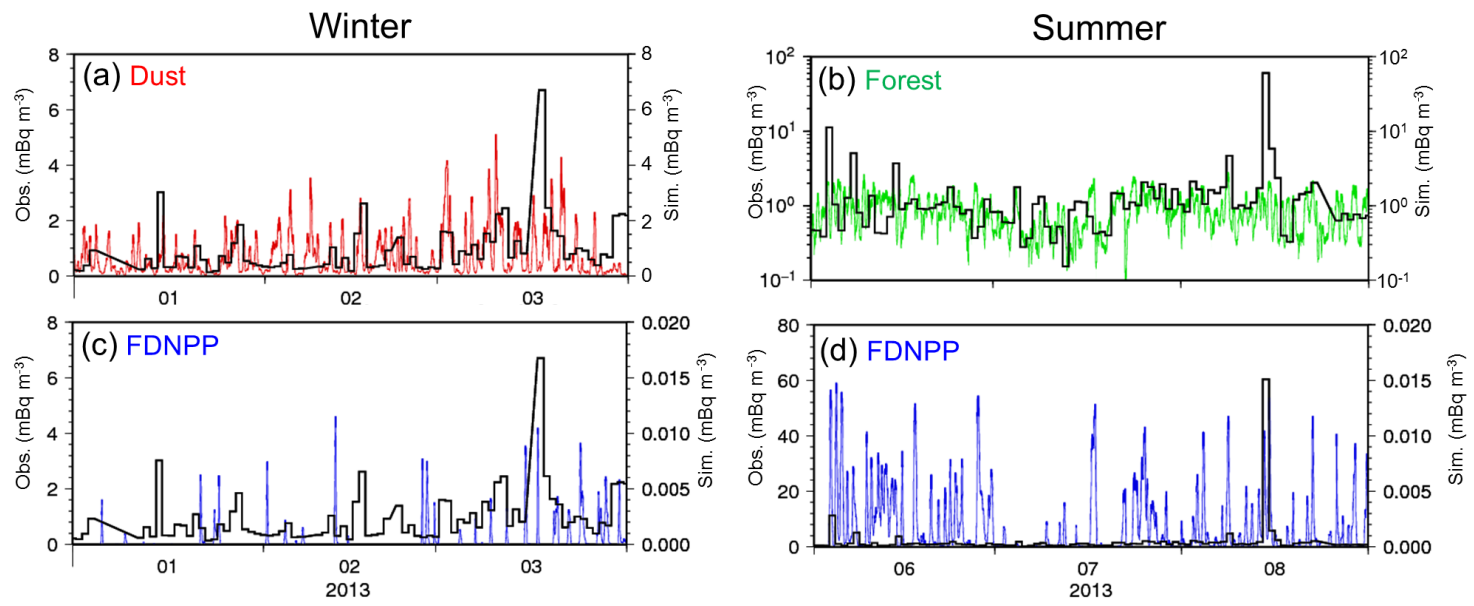

Figure 9. Time series of observed (black) and simulated (colors) ${ }^{137}$ Cs surface air concentration at Namie (a, c) in winter from January to March and (b, d) in summer from June to August 2013. The colors of the lines are the same as in Fig. 7 but the time variation is hourly. The shaded areas indicate the range of ${ }^{137} \mathrm{Cs}$ concentrations obtained when the simulations were run using the optimized parameter ranges $E_{\mathrm{c}}=0.03-0.05$ and $v_{\mathrm{d}}=0.05-0.1 \mathrm{~cm} \mathrm{~s}^{-1}$.

cussed in Sect. 5.2. The effects of other processes that were not considered in the model, such as land surface processes and decontamination, are discussed based on the dose rate measurements from the monitoring posts in Fukushima in Sect. 5.3. Future issues are summarized in Sect. 5.4.

\subsection{Seasonal variation and source contribution}

The discussion in this section expands on that in Sect. 4.2. Figure 9 shows the same temporal variation as Fig. 7 but for simulated (using the optimized ranges of parameters) results for ${ }^{137} \mathrm{Cs}$ from dust and FDNPP in winter (January to March) and from forest and FDNPP in summer (June to August).

In the winter, the simulated trend for dust agreed well with the observed trend (Fig. 9a), and the surface air concentration during this period was positively correlated with the surface wind speed in both the simulation $(R=0.88$ on an hourly basis) and the observations ( $R=0.32$ on a daily basis). There was a sporadic peak in the observational data of $6.7 \mathrm{mBq} \mathrm{m}^{-3}$ from the 17 March at 13:00 local time (LT) to 18 March at 13:00 LT that could not be reproduced by the dust module, and this peak coincided with a plume arriving from FDNPP, as shown in Fig. 9c. Therefore, the observed peak could be accounted for by specific re-suspension events on the order of $10^{9} \mathrm{~Bq} \mathrm{~h}^{-1}$ (the left axis divided by the right axis multiplied by $10^{6} \mathrm{~Bq} \mathrm{~h}^{-1}$ in Fig. 9c) if they occurred on the premises of FDNPP or close to the area. There are also two events exceeding $2 \mathrm{mBq} \mathrm{m}^{-3}$, one in January and another in February. It is unlikely that the two peaks originated from the direct emission from FDNPP and likely that they originated from the dust emission because the observed peaks coincided with the simulated dust peaks (Fig. 9a) and not with the simulated peaks due to the FDNPP emission (Fig. 9c).
In the summer, the simulated quantity as well as the variation in the forest data agreed well with the observed data (Fig. 9b). Because there is only monthly variation in the simulated emission, the simulated daily trend solely originated from variations in the meteorological parameters (wind field, turbulent mixing, and wet scavenging). A significant peak of $60.4 \mathrm{mBq} \mathrm{m}^{-3}$ is observed from 14 August at 13:00 LT to 15 August at 13:00 LT. This observed level was approximately 2 orders of magnitude larger than the simulated level and 1 to 2 orders of magnitude larger than the observed level for the other days in this period. Therefore, continuous emission such as re-suspension from forest is less likely to be the origin of the peak. Because the observed peak and the simulated peak of ${ }^{137} \mathrm{Cs}$ from FDNPP coincided (Fig. 9d), the observed level could be accounted for by specific re-suspension events on the order of $10^{10} \mathrm{Bqh}^{-1}$ either on the premises of FDNPP or close to the area. There have been several arguments that the observed peaks in August 2013 were associated with debris removal operations at FDNPP, and this is discussed separately in Sect. 5.2.

Figure 10 illustrates the seasonal mean surface wind vector and surface air ${ }^{137} \mathrm{Cs}$ concentration (simulated using the reference parameters) due to (a) dust re-suspension in the winter and (b) forest re-suspension in the summer. Due to the prevailing northwesterly winter monsoon, ${ }^{137} \mathrm{Cs}$ was carried southeastward in the winter. In the summer, under the influence of the Pacific high-pressure system, ${ }^{137} \mathrm{Cs}$ was carried inland. The monthly mean wind speed is high in winter and low in summer. The upper panels of Fig. 11 illustrate the observed and simulated (using the optimized ranges of parameters) total (from soil, forest, and FDNPP) ${ }^{137} \mathrm{Cs}$ concentration at Namie and Tsukuba. The time resolutions of the 


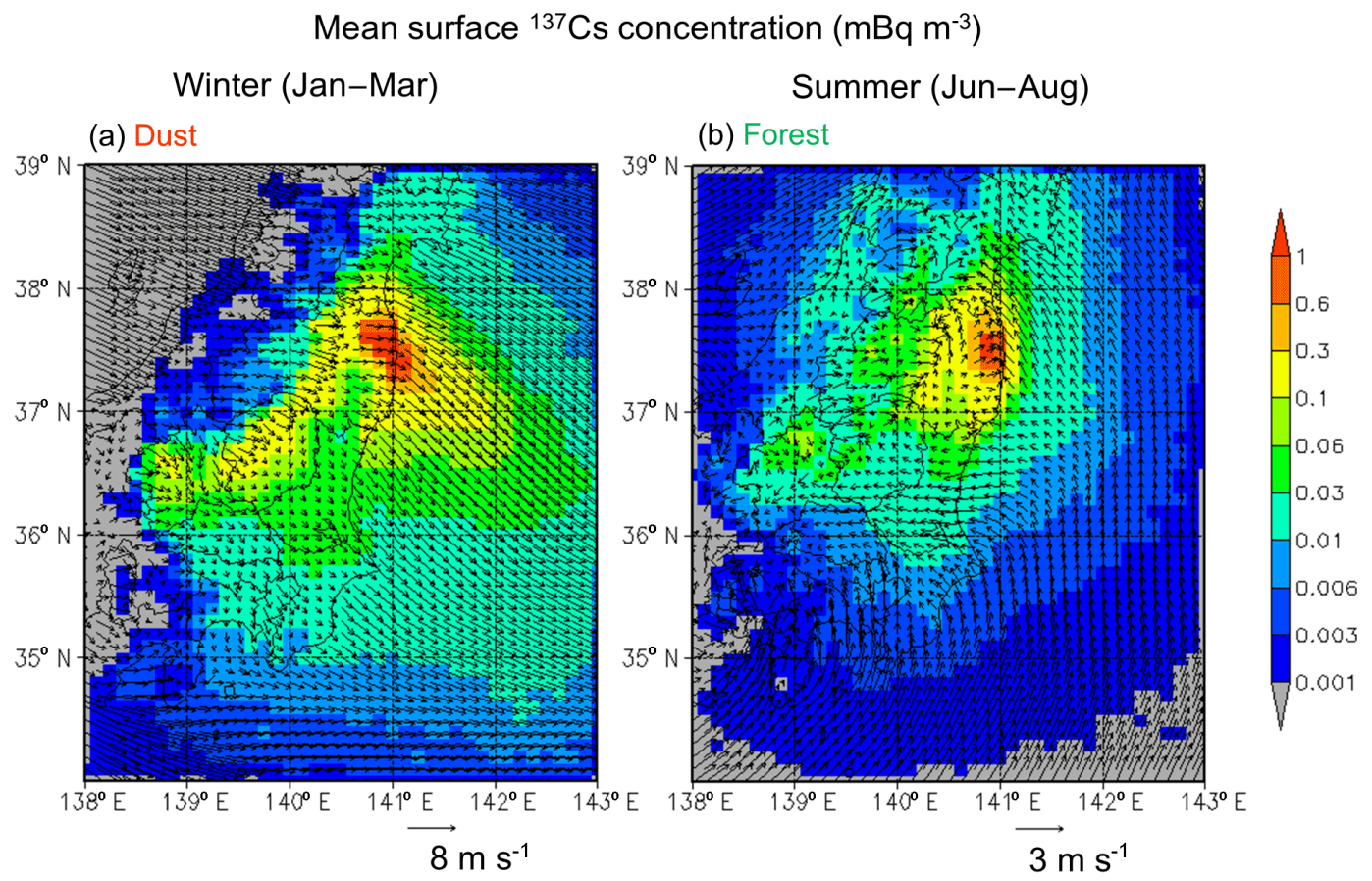

Figure 10. Seasonal mean surface (10 m above ground level) wind vector and ${ }^{137} \mathrm{Cs}$ surface concentration (a) due to dust re-suspension in winter from January to March and (b) due to forest re-suspension in summer from June to August. The deposition parameters of the simulation in the figure are $E_{\mathrm{c}}=0.04$ and $v_{\mathrm{d}}=0.1 \mathrm{~cm} \mathrm{~s}^{-1}$.

simulation are daily for Namie and weekly for Tsukuba to be consistent with the sampling intervals of the two respective sites. The simulation successfully reproduced the quantity and variation in the observed background concentration at Namie and Tsukuba but could not reproduce the sporadic peak events observed at Namie, as discussed above. The simulation also significantly underestimated the observations at Tsukuba from January to March, 2013. Due to the northwesterly monsoon (Fig. 10a), there was less air mass transported from FDNPP to Tsukuba in the winter and therefore this underestimation is probably due specifically to underestimation of the simulated re-suspension around Tsukuba. The lower panels of Fig. 11 show the relative contributions of ${ }^{137} \mathrm{Cs}$ from soil and forests at Namie and Tsukuba. The contribution from FDNPP was negligible throughout the year. At both sites, the contribution from dust was high $(0.7-0.9)$ in the cold season and low $(0.2-0.4)$ in the warm season due to higher surface wind speed in the cold season.

Figure 12a shows the observed and simulated (with the reference parameters) monthly Namie to Tsukuba ${ }^{137} \mathrm{Cs}$ concentration ratios. The mean concentration ratio exceeded 100 in June and 200 in August due to the sporadic peak events. The monthly median would be relevant for comparing the background observation with the simulation results by considering only continuous emission sources. The values of the simulated concentration ratio and its seasonal variation agreed fairly well with the observed monthly median ratio: the observed and simulated annual means were 38.9 and
31.1 , respectively. Figure $12 \mathrm{~b}$ shows the monthly mean simulated re-suspension source area contributions to the ${ }^{137} \mathrm{Cs}$ air concentration at Namie and Tsukuba. The re-suspension source area is defined as the model grid where the observed deposition amount exceeded $300 \mathrm{kBq} \mathrm{m}^{-2}$ (Fig. 4a) and includes the Namie grid $\left(2300 \mathrm{kBq} \mathrm{m}^{-2}\right)$. Eighty to $90 \%$ of the ${ }^{137} \mathrm{Cs}$ air concentration at Namie originated from the source region, and there was no clear seasonal variation in the value. In contrast, Tsukuba is characterized as a downwind region and there was clear seasonal variation in the source contribution ratio: high in summer and low in winter, due to the summer and winter monsoons, as discussed above. Nonetheless, the highest value at Tsukuba was 0.4 in July, and so more than half of the ${ }^{137} \mathrm{Cs}$ concentration at Tsukuba originated locally or from areas other than the contaminated regions throughout the year. As shown in Fig. 11a and b, the variability in the simulated concentration at Tsukuba due to uncertainty in the deposition parameters was much larger than that at Namie. The differences in the variability indicated that the Namie and Tsukuba sites can be characterized as the source area and the downwind area, respectively: as the time required for the plume to move from the emission site to the observation site increases, the variability becomes larger due to the increased chance for the plume to experience dry and wet scavenging. 


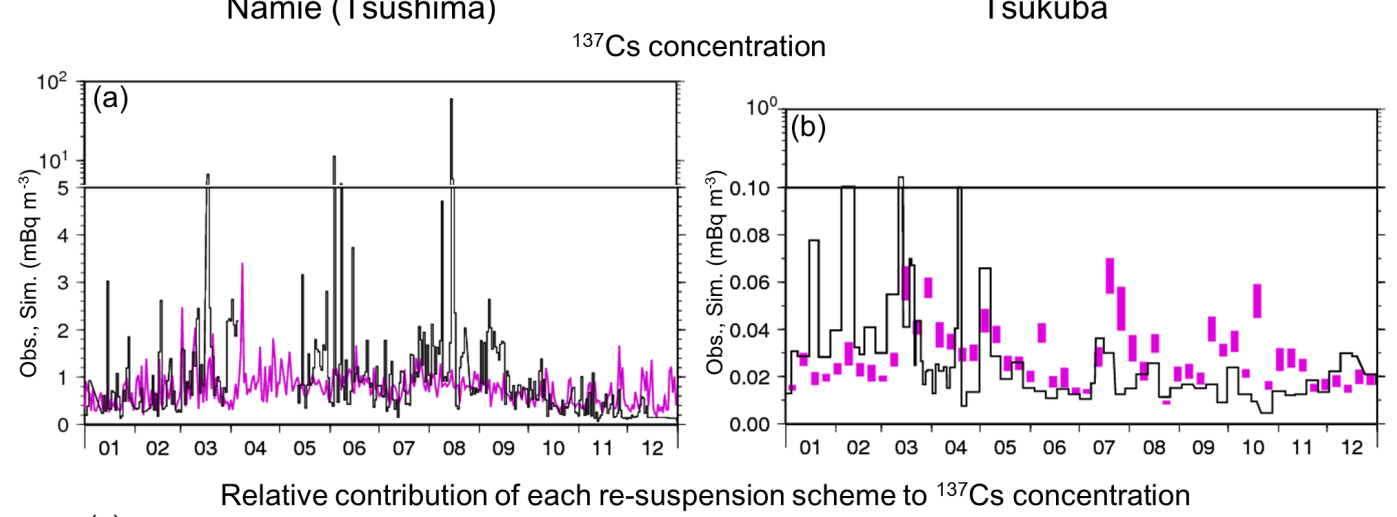

(c)
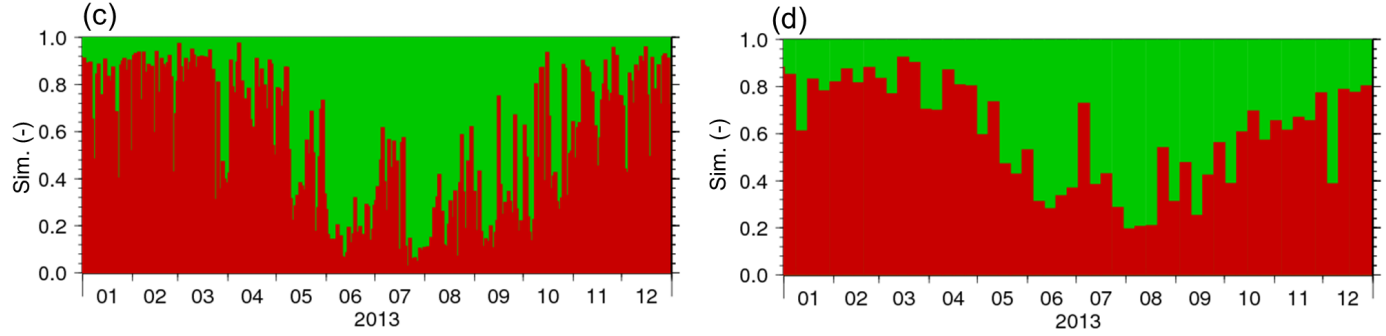

Figure 11. Time series of (a, b; black) the observed and (purple) the simulated surface ${ }^{137}$ Cs concentration due to total re-suspension and (c, d) the relative contribution of (red) dust and (green) forest re-suspension to the ${ }^{137} \mathrm{Cs}$ concentration at (a, c) Namie and (b, d) Tsukuba. The shaded areas of $(\mathbf{a})$ and $(\mathbf{b})$ indicate the range of ${ }^{137} \mathrm{Cs}$ concentrations obtained when the simulations were run using the optimized parameter ranges $E_{\mathrm{c}}=0.03-0.05$ and $v_{\mathrm{d}}=0.05-0.1 \mathrm{~cm} \mathrm{~s}^{-1}$.

(a) Namie (Tsushima) to Tsukuba ${ }^{137} \mathrm{Cs}$ ratio

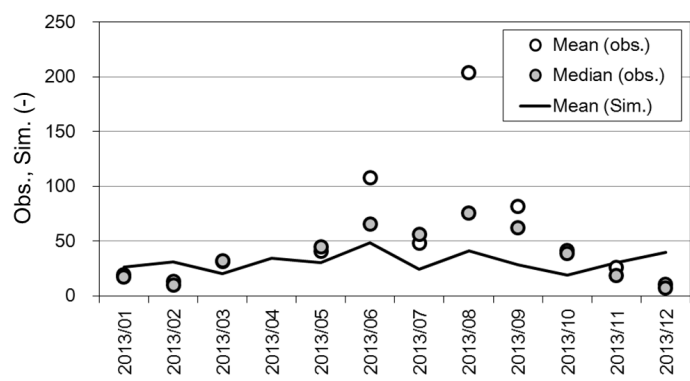

(b) Re-suspension source contribution of ${ }^{137} \mathrm{Cs}$

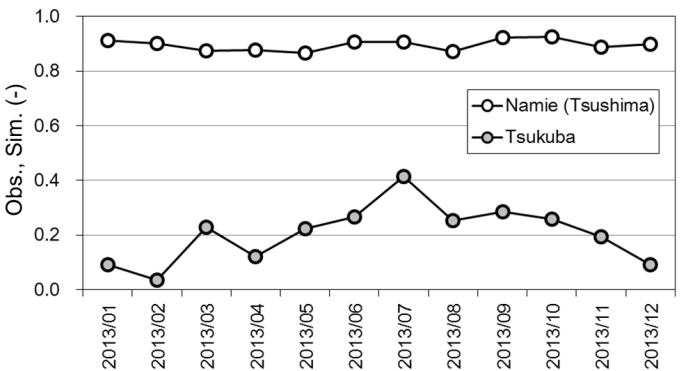

Figure 12. Monthly mean (a) observed mean, observed median and simulated Namie to Tsukuba ${ }^{137}$ Cs concentration ratio and (b) simulated re-suspension source area (where the observed deposition amount $>300 \mathrm{kBq} \mathrm{m}^{-2}$ ) contributions to ${ }^{137} \mathrm{Cs}$ air concentration at Namie and Tsukuba. The deposition parameters of the simulation in the figure are $E_{\mathrm{c}}=0.04$ and $v_{\mathrm{d}}=0.1 \mathrm{~cm} \mathrm{~s}^{-1}$.

\subsection{Possible source of sporadic peak events}

There have been several scientific studies and governmental reports on the unexpected re-suspension from FDNPP in August 2013. The high-dose-rate alarm was activated on August 19 within the premises of FDNPP associated with the debris removal operation. Matsunami et al. (2016) related the radiocesium contamination of brown rice in Fukushima in 2013 to this operation, whereas MAFF (2015) denied any association. The NRA estimated the ${ }^{137} \mathrm{Cs}$ emission rate during the debris removal operation as $6.7 \times 10^{10} \mathrm{~Bq} \mathrm{~h}^{-1}$ and the cumulative amount as $1.1 \times 10^{11} \mathrm{~Bq}(\mathrm{NRA}, 2014)$.
TEPCO (2014c) estimated the emission rate during the operation as $5.8 \times 10^{10}-1.2 \times 10^{11} \mathrm{~Bq} \mathrm{~h}^{-1}$ and the cumulative amount as $1.3-2.6 \times 10^{11} \mathrm{~Bq}$. Steinhauser et al. (2015) estimated the gross amount as $2.8 \times 10^{11} \mathrm{~Bq}$ using measurements of weekly air filter sampling and monthly deposition, and a numerical simulation. Their estimates are similar in magnitude to our estimate $\left(10^{10} \mathrm{~Bq} \mathrm{~h}^{-1}\right.$; see Sect. 5.1) but the dates are different: our observed peak was earlier than the reported removal operation.

Our daily sampling showed a peak concentration $\left(60.4 \mathrm{mBq} \mathrm{m}^{-3}\right)$ from 14 August at 13:00 LT to 15 August at 13:00 LT before the reported operation but did not detect high 


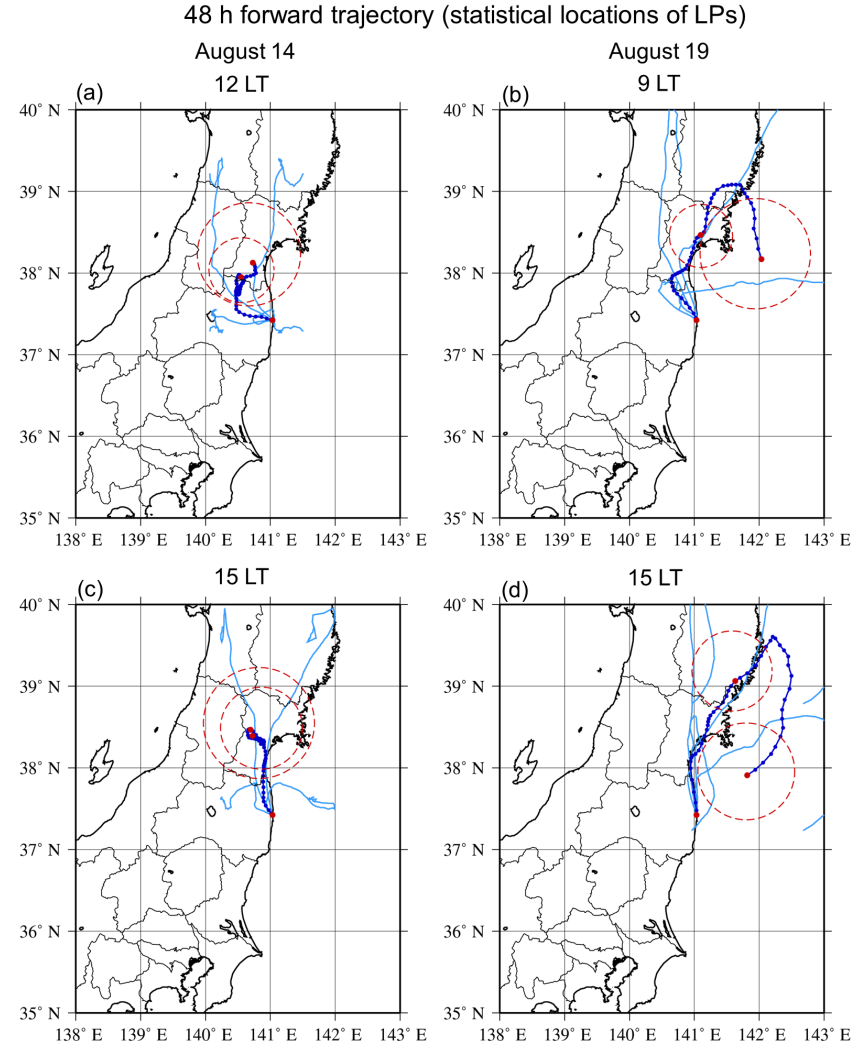

Figure 13. $48 \mathrm{~h}$ forward trajectory (statistical locations of LPs within $1 \mathrm{~km}$ AGL) predicted by the LM starting at (a) 12:00 LT and (c) 15:00 LT on 14 August and (b) 09:00 LT and (d) 15:00 LT on 19 August. Blue lines indicate median locations of LPs at $1 \mathrm{~h}$ and 1-day intervals as blue and red dots, respectively. Sky-blue lines indicate 17 th and 83 rd percentile locations of LPs and red dashed circles indicate areas containing $66 \%$ of the LPs.

concentrations in the 19 August $\left(0.33 \mathrm{mBq} \mathrm{m}^{-3}\right.$ for August 18 at 13:00 LT to 19 August at 13:00 LT and $1.2 \mathrm{mBq} \mathrm{m}^{-3}$ for 19 August at 13:00 to 20 August at 13:00 LT). Figure 13 shows the forward trajectories predicted by the LM (statistical locations of LPs) starting from FDNPP on 14 August (left) and 19 August (right). The sky-blue lines and red dashed circles indicate areas containing approximately two-thirds of the LPs within $1 \mathrm{~km}$ AGL: the extent of the area reflects horizontal and vertical atmospheric diffusion. The highest dose rate peaks were observed from 13:50 to $14: 10 \mathrm{LT}$ on 19 August at $2.8-8.3 \mathrm{~km}$ north and north-northwest of FDNPP on the leeward side, as reported by Fukushima prefecture (https://www.pref.fukushima.lg.jp/ download/1/20130827moni.pdf.pdf). The forward trajectories on 12 August indicated that plumes during the debris removal operation traveled north-northwest to north of FDNPP (Fig. 13b and d), rather than towards the west-northwest, where the Namie site is located. On 14 August, on the other hand, plumes were transported towards the west (starting at 12:00 LT, Fig. 13a), and then to the north (starting at (a) Daily mean dose rate in a coastal area in Fukushima (Hamadori)

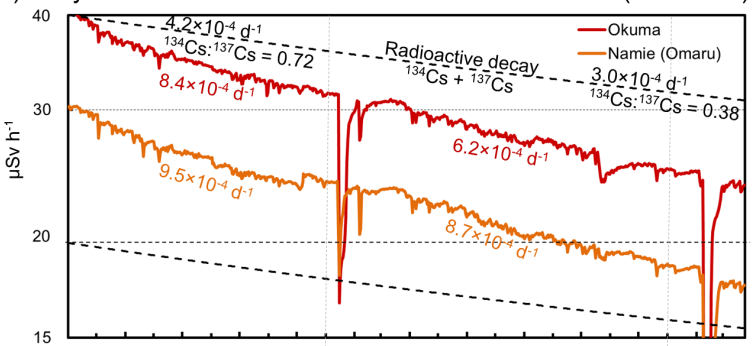

(b) Daily mean dose rate in a mountainous area in Fukushima (Abukuma)

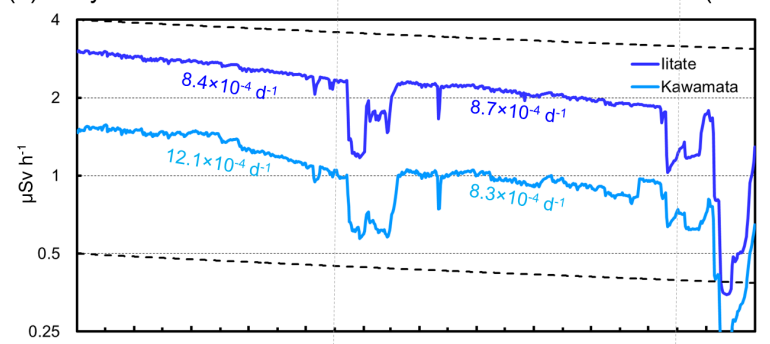

(c) Daily mean dose rate in a valley area in Fukushima (Nakadori)

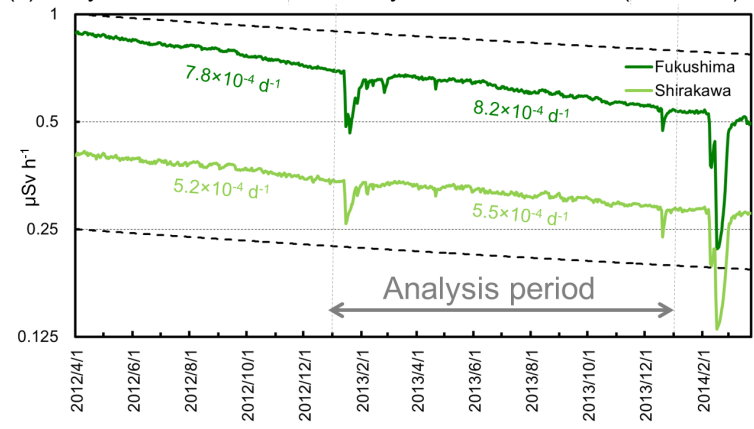

Figure 14. Daily mean gamma dose rate at the six monitoring sites: (a; red) Okuma and (orange) Namie (Omaru district) in the coastal area, (b; blue) village of Iitate and (sky blue) town of Kawamata in the Abukuma highland area, and (c; green) cities of Fukushima and (greenish yellow) Shirakawa in the Nakadori valley area of Fukushima prefecture as presented in Fig. 1b for two fiscal years (from April 2012 to March 2014). The first-order decreasing rates of the least-squares approximation over the period of no snow cover (May to October, 2012 and 2013) is also presented, along with the radioactive decay $\left({ }^{134} \mathrm{Cs}\right.$ plus ${ }^{137} \mathrm{Cs}$, by assuming the same amount of activity on 12 March 2011) in April 2012 and March 2013.

15:00 LT, Fig. 13c) due to fast changes in wind direction, resulting in the simulated peak concentration shown in Fig. 9d during this period. Our simulation and observations together indicated that the same order of magnitude of ${ }^{137} \mathrm{Cs}$ emission occurred on August 14-15 and on 19 August. Alarm activation was not reported on August 14-15, but debris removal operation was also conducted on August 14 and 16 (MAFF, 2015). 


\subsection{Land surface processes, decontamination, and dust emission suppression due to snow cover}

Figure 14 presents the time series of ambient gamma dose rates measured at the monitoring posts in Fukushima prefecture indicated in Fig. 1b. The data were obtained from the Nuclear Regulation Authority (NRA), Japan, website (http://radioactivity.nsr.go.jp/map/ja/index.html). A total of six monitoring posts, two from each of the three geographical areas (Hamadori coastal area, Abukuma highland area, and Nakadori valley area), were selected. There are tens to hundreds of monitoring posts in each municipality (village, town, and city) in Fukushima prefecture. We selected a monitoring post in each municipality by applying the following conditions: a post showing the highest dose rate of all posts in the municipality at the time of downloading (around 11:00, 28 December 2015), data are available since 1 April 2012, and the instruments are situated $100 \mathrm{~cm}$ above the ground.

In April 2012, the government of Japan designated the evacuation-directed zones as a difficult-to-return zone (DRZ; > $50 \mathrm{mSv} \mathrm{yr}^{-1} ; 9.55 \mu \mathrm{Sv} \mathrm{h}^{-1}$ ), a habitation-restricted zone (HRZ; $20-50 \mathrm{mSv} \mathrm{yr}^{-1}$; $3.85-9.55 \mu \mathrm{Sv} \mathrm{h}^{-1}$ ), and a zone being prepared to have the evacuation directive lifted ( $<20 \mathrm{mSv} \mathrm{yr}^{-1} ; 3.85 \mu \mathrm{Sv} \mathrm{h}^{-1}$ ) (METI, 2012). The two sites in the Hamadori area, Okuma and Omaru, have been designated DRZ (13.6 and $11.8 \mu \mathrm{Sv} \mathrm{h}^{-1}$ on 28 December 2015). The dose rates at the two sites in the Abukuma area, Iitate and Kawamata, dropped below the HRZ level during the analysis period in this study $\left(1.17\right.$ and $0.521 \mu \mathrm{Sv} \mathrm{h}^{-1}$ on $28 \mathrm{De}-$ cember 2015). The dose rates in the Nakadori area are below $1 \mu \mathrm{Sv} \mathrm{h}^{-1}$ (0.242 and $0.201 \mu \mathrm{Sv} \mathrm{h}^{-1}$ on 28 December 2015).

The dose rate significantly dropped when the ground was covered with snow, in January and December 2013 in Hamadori and Nakadori, and from January to early March and December 2013 in Abukuma (the elevation of Abukuma is $500-1000 \mathrm{~m}$ and higher than Hamadori and Nakadori). Snow cover suppresses re-suspension due to dust emission. Namie (Tsushima) is located in Abukuma and the ground was covered with snow until early March (Ishizuka et al., 2016). The observed air concentration of ${ }^{137} \mathrm{Cs}$ at Namie (Tsushima) was correlated with the wind speed in the winter from January to March, indicating that re-suspension during the period was mechanically induced. In the winter, dust resuspension from outside Abukuma, such as from Hamadori and Nakadori, or from land surface where the snow cover was partly melted due to solar radiation, might be the dominant source contributing to the ${ }^{137} \mathrm{Cs}$ surface air concentration at Namie (Tsushima) when the ground was covered with snow.

The first-order decreasing rates fitted by the least-squares approximation for the period without snow cover, May to October 2012 and 2013, are presented in Fig. 14. The rates ranged from 5.2 to $12.1 \times 10^{-4} \mathrm{day}^{-1}$. The monthly mean radioactive decay rates of total radiocesium $\left({ }^{134} \mathrm{Cs}+{ }^{137} \mathrm{Cs}\right)$, determined by assuming that the activities of ${ }^{134} \mathrm{Cs}$ and ${ }^{137} \mathrm{Cs}$ were equivalent in March 2011 , were $4.2 \times 10^{-4}$ and
$3.0 \times 10^{-4} \mathrm{day}^{-1}$ in April 2012 and March 2014, respectively, due to the difference in half-life of ${ }^{134} \mathrm{Cs}$ and ${ }^{137} \mathrm{Cs}$ (2.07 and 30.1 years, respectively). By assuming that the gamma dose rate primarily originated to radiation from the land surface radiocesium, the radioactive decay accounted for $35-50 \%$ of the decreasing rate of total ground radioactivity; the exception was Shirakawa, where radioactive decay accounted for $55-80 \%$ of the decrease. In other words, 50$65 \%$ of the ground radioactivity decrease was likely due to land surface processes, decontamination, and re-suspension to air. As discussed in Sect. 4.3, the estimated decreasing rate due to re-suspension was $2.7 \times 10^{-7}-8.2 \times 10^{-6}$ day $^{-1}$, which is 2 to 3 orders of magnitude smaller than the decreasing rates due to the other processes $\left(10^{-4}-10^{-3} \mathrm{day}^{-1}\right)$.

It is difficult to distinguish the contributions of land surface processes and decontamination. By subtracting the radioactive decay rate $\left(3.0-4.2 \times 10^{-4} \mathrm{day}^{-1}\right)$ and the decreasing rate due to re-suspension $\left(2.7 \times 10^{-7}-8.2 \times 10^{-6}\right.$ day $\left.^{-1}\right)$ from the gross decreasing rate $\left(5.2-12.1 \times 10^{-4} \mathrm{day}^{-1}\right)$, the estimated decreasing rates due to land surface processes and decontamination ranged from 1.0 to $7.9 \times 10^{-4} \mathrm{day}^{-1}$. Matsuda et al. (2015) summarized the depth profiles of radiocesium in soil at more than 80 locations in Fukushima, including Hamadori, Abukuma, and Nakadori. They found that the radiocesium levels have been slowly migrating downward, with rates ranging from 1.7 to $9.6 \mathrm{~kg} \mathrm{~m}^{-2} \mathrm{yr}^{-1}$ (equivalent to $1.1-6.0 \mathrm{~mm} \mathrm{yr}^{-1}$ for a dust particle density of $2650 \mathrm{~kg} \mathrm{~m}^{-3}$ and a porosity of $0.4 \mathrm{~m}^{3} \mathrm{~m}^{-3}$, for example). Evrard et al. (2015) summarized that significant transfer of particulate-bound radiocesium occurs during major rainfall and runoff events (e.g., typhoons and spring snowmelt). Together with the relaxation depth-dose rate relationship provided by Saito and Petoussi-Hess (2014), the decreasing rate due to land surface processes such as downward migration, runoff, and erosion could be quantified and thus the decontamination effect could be separately extracted.

\subsection{Future issues}

Issues that remain to be resolved in future research are summarized in this section. First of all, re-suspension from biota could be predominant in the warm season, but the resuspension sources as well as mechanisms remain essentially unknown. Further study is needed to understand the mechanism based on field experiments and numerical simulations. The current estimation could account for the measured background concentration $\left(0.1-1 \mathrm{mBq} \mathrm{m}^{-3}\right)$ but could not reproduce the observed sporadic peak concentration (1$10 \mathrm{mBq} \mathrm{m}^{-3}$ ) at the Namie site. Further study is needed to identify the cause. The dust flux module has been validated at a single location. The module needs to be improved to be applicable to various land use and soil texture conditions. The decontamination may reduce resuspension afterward, whereas the resuspension may occur during decontamination-related work. This effect should be evalu- 
ated in the future. The current estimation was based on a single model simulation. Variability in multi-model simulations is rather large (SCJ, 2014; Draxler et al., 2015) and therefore multi-model assessment will be indispensable for long-term re-suspension analysis.

\section{Conclusions}

The long-term effect of ${ }^{137} \mathrm{Cs}$ re-suspension from contaminated soil and biota due to the Fukushima nuclear accident has been quantitatively assessed using a numerical simulation, a field experiment on dust emission in the contaminated area (Namie, Fukushima), and air concentration measurements inside (Namie) and outside (Tsukuba, Ibaraki) of the area. The re-suspension mechanism remains unknown. We therefore utilized the observational data obtained both inside and outside the contaminated area, together with a transport model, to provide a robust budget analysis of the re-suspension, transport, and re-deposition of ${ }^{137} \mathrm{Cs}$ in the eastern part (the Tohoku and Kanto regions) of Japan. Our findings are summarized as follows:

1. Optimization of the deposition parameters of the LM for simulating the emergency situation of March 2011, using aircraft observation data (NRA, 2012) and the prescribed emission inventory (Katata et al., 2015), provided $0.1(0.05-0.1) \mathrm{cm} \mathrm{s}^{-1}$ for a dry deposition velocity over land and $0.04(0.03-0.05)$ for a hydrometeor collection efficiency for aerosols. The optimized (or validated) ranges of the deposition parameters were applied to long-term re-suspension assessment for the year 2013.

2. Using the dust emission module (Ishizuka et al., 2016), which was developed based on physical parameters, simulated ${ }^{137} \mathrm{Cs}$ re-suspension from soil multiplied by 5 accounted for the observed ${ }^{137} \mathrm{Cs}$ surface air concentration measured at Namie during only the cold season; the module underestimated the ${ }^{137} \mathrm{Cs}$ concentration by 1 to 2 orders of magnitude in the warm season.

3. Introducing re-suspension from forest using a constant re-suspension coefficient of $10^{-7} \mathrm{~h}^{-1}$ and monthly green area fraction could quantitatively account for the observed concentration together with its seasonal variation.
4. The contribution from additional emission from the reactor buildings of FDNPP $\left(10^{6} \mathrm{~Bq} \mathrm{~h}^{-1}\right)$ was negligible throughout the year and underestimated the observed air concentration by 2 to 3 orders of magnitude at both observation sites.

5. At Namie and Tsukuba, the simulated contribution of re-suspension from soil was high (0.7-0.9) in the cold season and low (0.2-0.4) in the warm season; the remaining contribution was from forest and was low in winter and high in summer. The contribution of the resuspension from the source area (where the aircraftobserved deposition exceeded $300 \mathrm{kBq} \mathrm{m}^{-2}$ ) to the air concentration at Namie was $0.8-0.9$ throughout the year, while that at Tsukuba varied from 0.1 to 0.4 , and was high in the summer and low in the winter.

6. The simulated annual total re-suspended amount for the whole region was $1.28 \mathrm{TBq}$, equivalent to $0.048 \%$ of the aircraft-observed total deposited amount of $2.68 \mathrm{PBq}$. The total re-deposition was $0.18-0.23 \mathrm{TBq}$, equivalent to $14.1-18.0 \%$ of the total re-suspended amount: the rest of the ${ }^{137} \mathrm{Cs}$ was transported out of the model domain. The spatial distribution of the decreasing rate of land surface ${ }^{137} \mathrm{Cs}$ due to re-suspension ranged from $2.7 \times 10^{-7}-8.2 \times 10^{-6} \mathrm{day}^{-1}$.

7. The first-order decrease rate of the ambient gamma dose rate in Fukushima prefecture ranged from 5.2 to $12.1 \times 10^{-4} \mathrm{day}^{-1}$. By subtracting the radioactive decay rate of $3.0-4.2 \times 10^{-4} \mathrm{day}^{-1}$, the ground radioactivity decay due to land surface processes, decontamination, and re-suspension was found to range from 1.0 to $7.9 \times 10^{-4}$ day $^{-1}$. The estimated re-suspension rate was 2 to 3 orders of magnitude lower than the decrease in rate due to the other processes, showing that re-suspension contributed negligibly towards reducing ground radioactivity.

\section{Data availability}

All data are available upon request to the authors. 


\section{Appendix A: Model description}

The current study employs a Lagrangian type model for the simulation of emission (either point sources or areal sources), horizontal and vertical diffusion and advection, gravitational settling, dry and wet depositions, and radioactive decay in the air. As described in Sect. 2.1, the current Lagrangian model (LM) uses simple parameterizations for dry and wet deposition schemes for computational efficiency, so longterm assessment and parameter sweep experiments are easily feasible. The source code for the model is open with the BSD 3-Clause License and is available on the web (https: //ebcrpa.jamstec.go.jp/isetr_a01-1/, in Japanese).

The coordinate system of the model is horizontal for longitude and latitude and vertical for pressure level, consistent with meteorological analysis data commonly used. The model can be driven only by fundamental meteorological parameters such as temperature, humidity, 3-D wind field, geopotential height, and surface precipitation provided by meteorological analysis data such as GPV-MSM. The model does not need to drive meteorological models to predict detailed meteorological variables such as cloud microphysics, turbulence quantities, and surface variables. Since the temporal and spatial resolution of the meteorological analysis is not very high (e.g., $3 \mathrm{~h}$ and $\sim 11 \mathrm{~km}$, respectively, for GPVMSM), linear interpolation is conducted in time and space. Alternatively, higher temporal and spatial resolution can be achieved by using a meteorological model. Furthermore, although currently not implemented, detailed variables predicted by a meteorological model can be used for more accurate predictions of turbulent diffusion, surface flux, and dry and wet deposition.

In the LM model, LPs are released constantly in time but the initial activity of LPs $\left(\mathrm{Bq} \mathrm{LP}^{-1}\right)$ differs according to the emission flux $\left(\mathrm{Bq} \mathrm{h}^{-1}\right)$. The initial positions of LPs were randomly distributed within a fixed volume (or line) of plume centered at a point emission source such as FDNPP for the primary emission case simulation, or randomly distributed within a horizontal model grid for the areal emission cases (such as re-suspension from soil and forest). LPs do not disappear unless transported across lateral and upper boundaries or if they reach the surface layer due to gravitational settling (technically, gravitational settling velocity in the surface layer is included in the dry deposition velocity). The other processes, such as dry deposition, wet deposition and radioactive decay, do not decrease the number of LPs but do decrease the radioactivity carried by LPs because LPs represent an air mass rather than an actual particle, except in the case of gravitational settling. The lowest level permitted for the position of LPs is set as $2 \mathrm{~m}$ AGL and LPs going down across the level due to vertical turbulent motion will rebound at the level and go up. An LP whose radioactivity is smaller than a preset value, i.e., $10^{-10} \mathrm{~Bq}$, due to deposition or radioactive decay will disappear from the computation to maintain computational efficiency, since the cost of the computation is proportional to the number of LPs in the model domain. To output the model results, the LP fields are converted to Eulerian concentration $\left(\mathrm{Bq} \mathrm{m}^{-3}\right)$ and deposition $\left(\mathrm{Bq} \mathrm{m}^{-2}\right)$ fields on a prescribed coordinate system of grids. In Lagrangian type models, the spatial resolution of tracer emission, concentration, and deposition fields can be set independent of each other and with the spatial resolution of meteorological fields. In the current implementation of the LM, the coordinate systems of meteorological fields and radioactivity fields are horizontally in common but vertically different: meteorological fields are provided on isobaric levels, whereas radioactivity fields are calculated on height AGL.

The horizontal and vertical diffusion calculation followed JMA (2008), using the horizontal diffusion scheme of Uliasz (1990) with a constant horizontal diffusivity of $5.864 \times 10^{4} \mathrm{~m}^{2} \mathrm{~s}^{-1}$ and using a vertical diffusivity calculated based on Louis et al. (1982; see Eqs. 8.1.8 through 8.1.15 of JMA, 2008, for details).

The wet scavenging rate $\Lambda_{\text {wet }}\left(\mathrm{s}^{-1}\right)$ is simply parameterized as a function of the surface precipitation rate $P$ $\left(\mathrm{mm} \mathrm{s}^{-1}\right)$ as

$\Lambda_{\text {wet }}=\frac{3}{4} \frac{E_{\mathrm{c}}\left(a_{\mathrm{m}}, r_{\mathrm{m}}\right)}{a_{\mathrm{m}}} P$,

where $E_{\mathrm{c}}$ is the collection efficiency of aerosols by the hydrometeor, and $a_{\mathrm{m}}$ and $r_{\mathrm{m}}$ are the mean radii of the hydrometeor and aerosols, respectively (JMA, 2008). Empirically, $a_{\mathrm{m}}$ is characterized by $P$ as

$a_{\mathrm{m}}=0.35 P^{0.25}$.

JMA (2008) uses 0.05 for $E_{\mathrm{c}}$. In the current study, instead of explicitly predicting $E_{\mathrm{c}}$, its range was set for the sensitivity tests as listed in Table 2.

Conceptually, Eq. (A1) is the formulation for the washout process, i.e., the collection of aerosols by the settling hydrometeor particles such as rain and snow. $a_{\mathrm{m}}$ and $E_{\mathrm{c}}$ should differ for rain and snow, but common parameters are used in the current simulation. Also, Eq. (A1) is not applicable for the rainout process, since this process-cloud condensation nuclei or ice nuclei activation and deposition via subsequent cloud microphysical processes is totally different from the washout process. Because meteorological models were not utilized in this study and thus only relative humidity and surface precipitation rate are available and no cloud microphysical information (such as hydrometeors mixing ratio in each model grid) is available, Eq. (A1) is applied for all the LPs located above the grid with $P$. In order to partly account for the rainout process, Eq. (A1) is not applied to LPs in a grid, where the relative humidity is lower than the minimum value, set as $95 \%$ in the simulation.

The dry deposition velocity $v_{\mathrm{d}}\left(\mathrm{m} \mathrm{s}^{-1}\right)$ of aerosols (or gases) is conventionally formulated, using an electrical analogy, as an inverse of the summation of resistances $\left(\mathrm{s} \mathrm{m}^{-1}\right)$ representing turbulent diffusion in the surface layer, Brownian diffusion (or molecular diffusion for gases), interaction 
with the land surface (soil, water, and vegetation), and gravitational settling for aerosols (e.g., Wesely and Hicks, 2000). Therefore, $v_{\mathrm{d}}$ is a function of height as well as of turbulent flux and surface conditions. Nevertheless, $v_{\mathrm{d}}$ is set as constant in the simulation, but the height dependency of $v_{\mathrm{d}}$ is considered in the dry scavenging rate $\Lambda_{\mathrm{dry}}\left(\mathrm{s}^{-1}\right)$, following Furuno et al. (1999) as

$\Lambda_{\mathrm{dry}}=\frac{2}{z_{\text {srf }}}\left(1-\frac{z}{z_{\text {srf }}}\right) v_{\mathrm{d}}$,

where $z$ is the height of the LP (m AGL) and $z_{\text {srf }}$ is the surface layer height set as $100 \mathrm{~m}$ AGL in the study. Instead of explicitly predicting $v_{\mathrm{d}}$, its range was set at around $0.1 \mathrm{~cm} \mathrm{~s}^{-1}$, a typical speed for a range of aerosols around $1 \mu \mathrm{m}$ in diameter, for the sensitivity tests, as listed in Table 2 . The value of $v_{\mathrm{d}}$ is applied over land, whereas $v_{\mathrm{d}}$ over the ocean is multiplied by 0.1 , because $v_{\mathrm{d}}$ over a flat surface is approximately 1 and 2 orders of magnitude smaller than $v_{\mathrm{d}}$ over short vegetation such as grass and tall vegetation such as forest, respectively (e.g., Petroff and Zhang, 2010).

\section{Appendix B: Statistical accuracy of the current simulation setting}

Because the statistical error of Lagrangian simulation is inversely proportional to the square of the number of LPs, the statistical accuracy of the current simulation setting was evaluated using the following measures (relative errors of quantities of the sensitivity runs to those of the reference run):

$E_{\text {con }}(x, y)=\frac{\left|C_{\text {sens }}(x, y)-C_{\text {ref }}(x, y)\right|}{C_{\text {ref }}(x, y)}$,
$E_{\text {dep }}(x, y)=\frac{\left|D_{\text {sens }}(x, y)-D_{\text {ref }}(x, y)\right|}{D_{\text {ref }}(x, y)}$,

where $x$ and $y$ indicate grid points on the longitudinal and latitudinal axes, respectively. $C_{\text {sens }}$ and $D_{\text {sens }}$ indicate temporal mean surface concentrations $\left(\mathrm{Bq} \mathrm{m}^{-3}\right)$ and temporal cumulative depositions $\left(\mathrm{Bq} \mathrm{m}^{-2}\right)$ of the sensitivity runs, respectively. $C_{\text {ref }}$ and $D_{\text {ref }}$ are the same as $C_{\text {sens }}$ and $D_{\text {sens }}$ but for the reference run. $E_{\text {con }}$ and $E_{\text {dep }}$ were sampled only at grids where $C_{\text {ref }}(x, y)$ and $D_{\text {ref }}(x, y)$ are greater than their areal mean values, respectively.

\section{B1 Point source case}

The number emission rate of LPs, $N_{\mathrm{LP}}$, was set as $32000 \mathrm{~h}^{-1}$ (i.e., $N_{\text {LP ref }}$ ) for a point source emission case such as the primary emission in March 2011 and additional emission from the reactor buildings in 2013. The median values together with the 25th and 75th percentile values of $E_{\text {con }}$ and $E_{\text {dep }}$ of the sensitivity runs (sensitivity to deposition parameters and sensitivity to $N_{\mathrm{LP}}$ ) against the reference run are listed on the rows of the top half of Table B1. Both $E_{\text {con }}$ and $E_{\text {dep }}$ of $N_{\text {LP_ref }} \times 4$ were significantly lower than those for the deposition parameters sensitivity run. This result indicates that $32000 \mathrm{~h}^{-1}$ for $N_{\mathrm{LP}}$ was sufficient to allow a statistically significant simulation for the purpose of this study, as shown in Figs. 4 and 5: the difference in concentration and deposition due to the deposition parameters was much larger than the difference due to model uncertainty in $N_{\mathrm{LP}} . E_{\mathrm{con}}$ and $E_{\mathrm{dep}}$ of $N_{\text {LP ref }} \times 0.25$ (which are also smaller than those of the deposition parameters sensitivity run) are larger than those of $N_{\text {LP_ref }} \times 4$, indicating fairly good accuracy convergence of the LM model.

\section{B2 Areal emission case}

$N_{\text {LP_ref }}$ was $16 \mathrm{~h}^{-1}$ grid $^{-1}$ for the areal emission case simulating re-suspension from soil and forests in 2013. The lower half of Table B1 is the same as the upper half except for the areal emission case (re-suspension from forest). Both $E_{\text {con }}$ and $E_{\text {dep }}$ of $N_{\mathrm{LP} \_ \text {ref }} \times 4$ were much lower than those for the deposition parameters sensitivity run, indicating that $16 \mathrm{~h}^{-1}$ grid $^{-1}$ supports a statistically significant simulation for the purpose of this study, as shown in Figs. 7-12. Usually, Lagrangian-type models are not appropriate for solving areal emission problems, because they require many more LPs for areal emission cases compared to point source cases and thus become computationally too expensive to obtain statistical accuracy (i.e., to set large number of LPs). In the case of this simulation, especially for the concentration, sensitivity to deposition parameters was much more significant than sensitivity to model uncertainty in $N_{\mathrm{LP}}$ using the sufficiently small number of $N_{\mathrm{LP} \_ \text {ref }}=16 \mathrm{~h}^{-1}$ grid $^{-1} . E_{\text {con }}$ and $E_{\text {dep }}$ of $N_{\text {LP_ref }} \times 4$ are smaller than those of $N_{\text {LP_ref }} \times 0.25$, indicating fair accuracy convergence of the LM model. 
Table B1. Statistical measures of temporal mean ${ }^{137}$ Cs surface concentration $\left(E_{\text {con }}\right)$ and cumulative deposition $\left(E_{\text {dep }}\right)$ of the sensitivity runs against the reference run for (top) the point source case and (bottom) the areal emission case.

\begin{tabular}{|c|c|c|c|c|c|}
\hline & $\begin{array}{r}\text { Number emission } \\
\text { rate of LP, } N_{\mathrm{LP}} \\
\left(\mathrm{h}^{-1} \mathrm{grid}^{-1}\right)\end{array}$ & $\begin{array}{l}E_{\mathrm{c}}^{\mathrm{a}} \\
(-)\end{array}$ & $\begin{array}{r}v_{\mathrm{d}}^{\mathrm{b}} \\
\left(\mathrm{cm} \mathrm{s}^{-1}\right)\end{array}$ & $\begin{array}{r}\text { Median } \\
(25 \text { th-75th percentile) } \\
\text { of } E_{\text {con }}^{\mathrm{c}}(\%)\end{array}$ & $\begin{array}{r}\text { Median } \\
\text { (25th-75th percentile) } \\
\text { of } E_{\mathrm{dep}}^{\mathrm{d}}(\%)\end{array}$ \\
\hline \multicolumn{6}{|c|}{ Point source case, March 2011} \\
\hline Reference run & 32000 & 0.04 & 0.01 & - & - \\
\hline \multicolumn{6}{|l|}{ Sensitivity runs } \\
\hline Deposition parameters & 32000 & $0.03-0.05$ & $0.05-0.01$ & $2.7(0.37-5.0)$ & $7.5(3.6-13)$ \\
\hline$N_{\text {LP_ref }} \times 4$ & 128000 & 0.04 & 0.01 & $0.51(0.21-0.96)$ & $0.72(0.32-1.5)$ \\
\hline$N_{\text {LP_ref }} \times 0.25$ & 8000 & 0.04 & 0.01 & $0.95(0.39-1.8)$ & $1.6(0.73-2.9)$ \\
\hline \multicolumn{6}{|c|}{$\begin{array}{l}\text { Areal emission case, } 2013 \\
\text { (re-suspension from forest) }\end{array}$} \\
\hline Reference run & 16 & 0.04 & 0.10 & - & - \\
\hline \multicolumn{6}{|l|}{ Sensitivity runs } \\
\hline Deposition parameters & 16 & $0.03-0.05$ & $0.05-0.01$ & $7.3(2.6-13)$ & $7.7(3.6-17)$ \\
\hline$N_{\text {LP_ref }} \times 4$ & 64 & 0.04 & 0.10 & $0.39(0.17-0.78)$ & $2.0(1.3-2.6)$ \\
\hline$N_{\text {LP_ref }} \times 0.25$ & 4 & 0.04 & 0.10 & $0.78(0.34-1.5)$ & $2.3(1.5-3.1)$ \\
\hline
\end{tabular}

${ }^{\mathrm{a}}$ Collection efficiency; see Eq. (A1). ${ }^{\mathrm{b}}$ Dry deposition velocity over land; see Eq. (A3). ${ }^{\mathrm{c}}$ Relative errors of temporal mean surface concentration at each grid cell of the sensitivity run to that of the reference run; see Eq. (B1). ${ }^{\mathrm{d}}$ Same as $E_{\mathrm{con}}$ but for cumulative deposition; see Eq. (B2). 
Acknowledgements. This research was mainly supported by Grants-in-Aid for Scientific Research on Innovative Areas (JP24110002 and JP20110003) from the Ministry of Education, Culture, Sports, Science and Technology (MEXT), and partly supported by the Japan Society for the Promotion of Science (JSPS), Ministère des Affaires Étrangères et du Développement International (MAEDI) under the Japan-France Integrated Action Program (SAKURA), as well as by KAKENHI grant numbers JP15K16121, JP24340115, and JP26310201 from MEXT. Partial expenses were covered by the Japanese Radioactivity Survey from the NRA, Japan. The authors are grateful for useful discussions with and comments from Yuichi Moriguchi of University of Tokyo, Hiromi Yamazawa of Nagoya University, and Haruo Tsuruta of Remote Sensing Technology Center of Japan (RESTEC). The authors are thankful to Masayuki Takigawa of JAMSTEC for the maintenance of the website of LM. The LM was developed by M. Inatsu, C. Yoshikawa, M. Takigawa, and M. Kajino.

Edited by: Y. Balkanski

Reviewed by: three anonymous referees

\section{References}

Adachi, K., Kajino, M., Zaizen, Y., and Igarashi, Y.: Emission of spherical cesium-bearing particles from an early stage of the Fukushima nuclear accident, Scientific Report, 3, 2554, doi:10.1038/srep02554, 2013.

Chino, M., Nakayama, H., Nagai, H., Terada, H., Katata, G., and Yamazawa, H.: Preliminary estimation of release amounts of ${ }^{131} \mathrm{I}$ and ${ }^{137} \mathrm{Cs}$ accidentally discharged from the Fukushima Daiichi nuclear power plant into atmosphere, J. Nucl. Sci. Technol., 48, 1129-1134, 2011.

Danielache, S. O., Yoshikawa, C., Priyadarshi, A., Takemura, T., Ueno, Y., Thiemens, M. H., and Yoshida, N.: An estimation of the radioactive ${ }^{35} \mathrm{~S}$ emitted into the atmospheric from the Fukushima Daiichi Nuclear Power Plant by using a numerical simulation global transport, Geochem. J., 46, 355-339, 2012.

Danielache, S. O., Yoshikawa, C., Kajino, M., Itou, S., Kakeya, W., Yoshida, N., and Igarashi, Y.: Radioactive ${ }^{35} \mathrm{~S}$ emitted from the Fukushima Nuclear Power Plan studied by a modified regional model, in preparation, Atmos. Chem. Phys., 2016.

Draxler, R., Arnold, D., Chino, M., Galmarini, S., Hort, M., Jones, A., Leadbetter, S., Malo, A., Maurer, C., Rolph, G., Saito, K., Servranckx, R., Shimbori, T., Solazzo, E., and Wotawa, G.: World Meteorological Organization's model simulations of the radionuclide dispersion and deposition from the Fukushima Daiichi nuclear power plant accident, J. Environ. Radioact., 139, 172-184, 2015.

Evangeliou, N., Balkanski, Y., Cozic, A., and Møller, A. P.: Global and local cancer risks after the Fukushima Nuclear Power Plant accident as seen from Chernobyl: A modeling study for radiocaesium $\left({ }^{134} \mathrm{Cs} \&{ }^{137} \mathrm{Cs}\right)$, Environ. Int., 64, 17-27, 2014.

Evrard, O., Laceby, J. P., Lepage, H., Onda, Y., Cerdan, O., and Ayrault, S.: Radiocesium transfer from hillslopes to the Pacific Ocean after the Fukushima Nuclear Power Plant accident: A review, J. Environ. Radioact., 148, 92-110, 2015.

Furuno, A., Chino, M., and Yamazawa, H.: Worldwide version of System of Prediction of Environmental Emergency Dose In- formation (WSPEEDI) Model Code (II) - Three-dimensional Atmospheric Dispersion Model for Synoptic Scale: GEARN, JAERI-Data/Code 99-044, Japan Atomic Energy Research Institute, Japan, 68 pp., 1999 (in Japanese).

Garger, E. K., Paretzke, H. G., and Tschiersch, J.: Measurement of resuspended aerosol in the Chernobyl area, Part III: size distribution and dry deposition velocity of radioactive particles during anthropogenic enhanced resuspension, Radiat. Environ. Bioph., 37, 201-208, 1998.

Garger, E. K., Kuzmenko, Y. I., Sickinger, S., and Tschiersch, J.: Prediction of the ${ }^{137} \mathrm{Cs}$ activity concentration in the atmospheric surface layer of the Chernobyl exclusion zone, J. Environ. Radioact., 110, 53-58, 2012.

Girard, S., Mallet, V., Korsakissok, I., and Mathieu, A.: Emulation and Sobl' sensitivity analysis of an atmospheric dispersion model applied to the Fukushima nuclear accident, J. Geophys. Res., 121, 3484-3496, doi:10.1002/2015JD023993, 2016.

Groëll J., Quélo, D., and Mathieu, A.: Sensitivity analysis of the modelled deposition of ${ }^{137} \mathrm{Cs}$ on the Japanese land following the Fukushima accident, Int. J. Environ. Pollut., 55, 67-75, 2014.

Gutman, G. and Ignatov, A.: The derivation of green vegetation fraction from NOAA/AVHRR data for use in numerical weather prediction models, Int. J. Remote Sens., 19, 1533-1543, 1998.

Hatano, Y. and Hatano N.: Formula for the resuspension factor and estimation of the date of surface contamination, Atmos. Environ., 37, 3475-3480, 2003.

Hirao, S., Yamazawa, H., and Nagae, T.: Estimation of release rate of iodine-131 and cesium-137 from the Fukushima Daiichi nuclear power plant, J. Nucl. Sci. Technol., 50, 139-147, doi:10.1080/00223131.2013.757454, 2013.

Holländer, W. and Garger, E.: Contamination of Surface by Resuspended Material, ECP-1, Final Report, Rep. EUR 16527, Office for Official Publications of the European Communities, Luxembourg, 1996.

Hososhima, M. and Kaneyasu, N.: Altitude-dependent distribution of ambient gamma dose rates in mountainous area of Japan caused by the Fukushima nuclear accident, Environ. Sci. Technol., 49, 3341-3348, 2015.

Igarashi, Y., Kajino, M., Zaizen, Y., Adachi, K., and Mikami, M.: Atmospheric radioactivity over Tsukuba, Japan: a summary of three years of observations after the FDNPP accident, Prog. Earth Planet. Sci., 2, 19 pp., doi:10.1186/s40645-015-0066-1, 2015.

Ishizuka, M, Mikami, M., Tanaka, T. Y., Igarashi, Y., Kita, K., Yamada, Y., Yoshida, N., Toyoda, S., Satou, Y., Kinase, T., Ninomiya, K., and Shinohara, A.: Use of a size-resolved 1-D resuspension scheme to evaluation resuspended radioactive material associated with mineral dust particles from the ground surface, J. Environ. Radioact., 13 pp., doi:10.1016/j.jenvrad.2015.12.023, 2016.

JMA: Japan Meteorological Agency's Non-Hydrostatic Model II, Suuchi Yohoka Hokoku Bessatsu (Additional Volume to Report of Numerical Prediction Division) 54, 265 pp., 2008 (in Japanese).

Kaneyasu, N., Ohashi, H., Suzuki, F., Okada, T., and Ikemori, F.: Sulfate aerosol as a potential transport medium of radiocesium from the Fukushima nuclear accident, Environ. Sci. Technol. 46, 5720-5726, 2012.

Katata, G., Terada, H., Nagai, H., and Chino, M.: Numerical reconstruction of high dose rate zones due to the Fukushima Daiichi 
Nuclear Power Plant accident, J. Environ. Radioact., 111, 2-12, 2012a.

Katata, G., Ota, M., Terada, H., Chino, M., and Nagai, H.: Atmospheric discharge and dispersion of radionuclides during the Fukushima Dai-ichi Nuclear Power Plant accident, Part I: Source term estimation and local-scale atmospheric dispersion in early phase of the accident, J. Environ. Radioact., 109, 103-113, doi:10.1016/j.jenvrad.2012.02.006, 2012b.

Katata, G., Chino, M., Kobayashi, T., Terada, H., Ota, M., Nagai, H., Kajino, M., Draxler, R., Hort, M. C., Malo, A., Torii, T., and Sanada, Y.: Detailed source term estimation of the atmospheric release for the Fukushima Daiichi Nuclear Power Station accident by coupling simulations of an atmospheric dispersion model with an improved deposition scheme and oceanic dispersion model, Atmos. Chem. Phys., 15, 1029-1070, doi:10.5194/acp15-1029-2015, 2015.

Kinase, T., Kita, K. Igarashi, Y., Adachi, K., Ninomiya, K., Shinohara, A., Okochi, H., Ogata, Y., Ishizuka, M., Toyoda, S., Yamada, K., Yoshida, N., Zaizen, Y., Mikami, M., Demizu, H., and Onda, Y.: Seasonal variation in activity concentration of atmospheric ${ }^{134,137} \mathrm{Cs}$ and their possibile resuspension host aerosol observed at Tsuahima and Yamakiya, Fukushima, Prog. Earth Planet. Sci., in review, 2016.

Kristiansen, N. I., Stohl, A., Olivié, D. J. L., Croft, B., Søvde, O. A., Klein, H., Christoudias, T., Kunkel, D., Leadbetter, S. J., Lee, Y. H., Zhang, K., Tsigaridis, K., Bergman, T., Evangeliou, N., Wang, H., Ma, P.-L., Easter, R. C., Rasch, P. J., Liu, X., Pitari, G., Di Genova, G., Zhao, S. Y., Balkanski, Y., Bauer, S. E., Faluvegi, G. S., Kokkola, H., Martin, R. V., Pierce, J. R., Schulz, M., Shindell, D., Tost, H., and Zhang, H.: Evaluation of observed and modelled aerosol lifetimes using radioactive tracers of opportunity and an ensemble of 19 global models, Atmos. Chem. Phys., 16, 3525-3561, doi:10.5194/acp-16-3525-2016, 2016.

Loosmore, G. A. and Hunt, J. R.: Dust resuspension without saltation, J. Geophys. Res., 105, 20663-20671, doi:10.1029/2000JD900271, 2002.

Louis, J. F., Tiedtke, M., and Geleyn, J. F.: A short history of the PBL parameterization at ECMWF, Workshop on planetary boundary layer parameterization, ECMWF, 59-80, 1982.

MAFF (Ministry of Agriculture, Forestry and Fisheries): Fukushima Prefecture, Tohoku Agricultural Research Center, National Institute for Agro-Environmental Sciences: Investigation of the cause for brown rice exceeding the allowable radiocesium concentration, available at: http://www.maff.go.jp/ j/kanbo/joho/saigai/fukusima/pdf/150526_youin_chosa.pdf (last access: 26 July 2016), 2015 (in Japanese).

Masson, O., Baeza, A., Bieringer, J., Brudecki., Bucci, S., Cappai, M., Carvalho, F. P., Connan, O., Cosma, C., Dalheimer, A., Didier, D., Depuydt, G., De Geer, L. E., De Vismes, A., Gini, L., Groppi, F., Gudnason, K., Gurriaran, R., Hainz, D., Halldórsson, O., Hammond, D., Hanley, O., Holey, K., Homoki, Zs., Ioannidou, A., Isajenko, K., Jankovic, M., Katzlberger, C., Kettunen, M., Kierepko, R., Kontro, R., Kwakman, P. J. M., Lecomte, M., Leon Vintro, L., Leppänen, A.-P., Lind, B., Lujaniene, G., Mc Ginnity, P., Mc Mahon, C., Malá, H., Manenti, S., Manolopoulou, M., Mattila., A., Mauring., A., Mietelski, J. W., Moller, B., Nielsen, S. P., Nikolic, J., Overwater, R. M. W., Pálsson, S. E., Papastefanou, C., Penev, I., Pham, M. K., Povinec, P. P., Ramebäck, H., Reis, M. C., Ringer, W., Rodriguez, A., Ru- lik, P., Saey, P. R. J., Samsonov, V., Schlosser, C., Sgorbati, G., Silobritiene, B. V., Söderström, C., Sogni, R., Solier, L., Sonck, M., Steinhauser, G., Steinkopff, T., Steinmann, P., Stoulos, S., Sýkora, I., Todorovic, D., Tooloutalaie, N., Tositti, L., Tschiersch, J., Ugron, A., Vagena, E., Vargas, A., Wershofen, H., and Zhukova, O.: Tracking of Airborne Radionuclides from the Damaged Fukushima Dai-Ichi Nuclear Reactors by European Networks, Environ. Sci. Technol., 45, 7670-7677, 2011.

Masson, O., Ringer, W., Malá, H., Rulik, P., Dlugosz-Lisiecka, M., Eleftheriadis, K., Meisenberg, O., De Vismes-Ott, A., and Gensdarmes, F.: Size distribution of airborne radionuclides from the Fukushima Nuclear Accident at several places in Europe, Environ. Sci. Technol., 47, 10995-11003, 2013.

Matsunami H., Murakami, T., Fujiwara, H., and Shinano, T.: Evaluation of the cause of unexplained radiocaesium contamination of brown rice in Fukushima in 2013 using autoradiography and gamma-ray spectrometry, Sci. Rep., 6, 20386, doi:10.1038/srep20386, 2016.

METI (Ministry of Economy, Trade and Industry): Convention on Nuclear Safety National Report of Japan for the Second Extraordinary Meeting, July 2012, Government of Japan, available at: http://warp.da.ndl.go.jp/info:ndljp/pid/3512451/www. meti.go.jp/english/press/2012/pdf/0705_01b.pdf (last access: 26 July 2016), 2012.

Miller, D. A. and White, R. A.: A conterminous United States multilayer soil characteristics data set for regional climate and hydrology modeling, Earth Interact., 2, 1-26, 1998.

Matsuda, N., Mikami, S., Shimoura, S., Takahashi, J., Nakano, M., Shimada, K., Uno, K., Hagiwara, S., and Saito, K.: Depth profiles of radioactive cesium in soil using a scraper plate over a wide area surrounding the Fukushima Dai-ichi Nuclear Power Plant, Japan, J. Environ. Radioact., 139, 427-434, 2015.

Morino, Y., Ohara, T., and Nishizawa, M.: Atmospheric behavior, deposition, and budget of radioactive materials from the Fukushima Daiichi nuclear power plant in March 2011, Geophys. Res. Lett. 38, L00G11, doi:10.1029/2011GL048689, 2011.

Morino, Y., Ohara, T., Watanabe, S., Hayashi, S., and Nishizawa, M.: Episode analysis of deposition of radiocesium from the Fukushima Daiichi Nuclear Power Plant accident, Environ. Sci. Technol., 47, 2314-2322, 2013.

NRA (Nuclear Regulation Authority): Airborne Monitoring Results in each prefecture, available at: http://radioactivity.nsr.go.jp/en/ list/203/list-1.html (last access: 26 July 2016), 2012.

NRA: Assessment of radionuclide emission involved in the debris removal operations for reactor 3 ; Handout for the 28th meeting on the supervision of a specific nuclear facility, available at: http: //www.nsr.go.jp/data/000051154.pdf (last access: 26 July 2016), 2014 (in Japanese).

Ohmori, Y., Kajikawa, M., Nishida, S., Tanaka, N., Kobayashi, N. I., Tanoi, K., Furukawa, J., and Fujiwara, T.: The effect of fertilization on cesium concentration of rice grown in a paddy field in Fukushima Prefecture in 2011 and 2012, J. Plant Res., 127, 67-71, 2014.

Oura, Y., Ebihara, M., Tsuruta, H., Nakajima, T., Ohara, T., Ishimoto, M., Sawahata, H., Katsumura, Y., and Nitta, W.: A database of hourly atmospheric concentrations of radiocesium $\left({ }^{134} \mathrm{Cs}\right.$ and $\left.{ }^{137} \mathrm{Cs}\right)$ in suspended particulate matter collected in March 2011 at 99 air pollution monitoring stations in Eastern 
Japan, Journal of Nuclear and Radiochemical Sciences, 15, 1526, 2015.

Petroff, A. and Zhang, L.: Development and validation of a size-resolved particle dry deposition scheme for application in aerosol transport models, Geosci. Model Dev., 3, 753-769, doi:10.5194/gmd-3-753-2010, 2010.

Pöhlker C., Wiedemann, K. T., Sinha, B., Shiraiwa, M., Gunthe, S. S., Smith, M., Su, H., Artaxo, P., Chen, Q., Cheng, Y., Elbert, W., Gilles, M. K., Kilcoyne, A. L. D., Moffet, R. C., Weigand, M., Matin, S. T., Pöschl, U., and Andreae, M. O.: Biogenic potassium salt particles as seeds for secondary organic aerosol in the Amazon, Science, 337, 1075-1078, 2012.

Quérel, A., Roustan, Y., Quélo, D., and Benoit, J. -P.: Hints to discriminate the choice of wet deposition models applied to an accidental radioactive release, Int. J. Environ. Pollut., 58, 268-279, 2015.

Saito, K. and Petoussi-Henss, N.: Ambient dose equivalent conversion coefficients for radionuclides exponentially distributed in the ground, J. Nucl. Sci. Techonol., 51, 1274-1287, doi:10.1080/00223131.2014.919885, 2014.

Saito, K., Shimbori, T., and Draxler, R.: JMA's regional atmospheric transport model calculations for the WMO technical task team on meteorological analyses for Fukushima Daiichi Nuclear Power Plant accident, J. Environ. Radioact., 139, 185-199, 2015.

Saunier, O., Mathieu, A., Didier, D., Tombette, M., Quélo, D., Winiarek, V., and Bocquet, M.: An inverse modeling method to assess the source term of the Fukushima Nuclear Power Plant accident using gamma dose rate observations, Atmos. Chem. Phys., 13, 11403-11421, doi:10.5194/acp-13-11403-2013, 2013.

SCJ (Science Council of Japan): A review of the model comparison of transportation and deposition of radioactive materials released to the environment as a result of the Tokyo Electric Power Company's Fukushima Daiichi Nuclear Power Plant accident, available at: http://www.scj.go.jp/ja/info/kohyo/ pdf/kohyo-22-h140902-e1.pdf (last access: 26 July 2016), 2014.

Sekiyama, T. T., Kunii, M., Kajino, M., and Shimbori, T.: Horizontal resolution dependence of atmospheric simulations of the Fukushima nuclear accident using $15 \mathrm{~km}, 3 \mathrm{~km}$, and $500 \mathrm{~m}$ grid models, J. Meteor. Soc. Japan, 93, 49-64, 2015.

Sekiyama, T. T., Kajino, M., and Kunii, M.: Ensemble dispersion simulation of a point-source radioactive aerosol using a square root Kalman filter, J. Geophys. Res., in review, 2016.

Skamarock, W. C., Klemp, J. B., Dudhia, J., Grill, D. O., Barker, D. M., Duda, M. G., Huang, X. Y., Wang, W., and Powers, J. G.: A description of the advanced research WRF version 3, Tech. Note, NCAR/TN475+STR, 125 pp., Natl. Cent. For Atmos. Res., Boulder, Colo., 2008.

Steinhauser, G., Niisoe, T., Harada, K. H., Shozugawa, K., Schneider, S., Synal, H.-A, Walther, C., Christl, M., Nanba, K., Ishikawa, H., and Koizumi, A: Post-accident sporadic releases of airborne radionuclides from the Fukushima Daiichi Nuclear Power Plant Site, Environ. Sci. Technol., 49, 14028-14035, doi:10.1021/acs.est.5b03155, 2015.

Stohl, A., Seibert, P., Wotawa, G., Arnold, D., Burkhart, J. F., Eckhardt, S., Tapia, C., Vargas, A., and Yasunari, T. J.: Xenon133 and caesium-137 releases into the atmosphere from the Fukushima Dai-ichi nuclear power plant: determination of the source term, atmospheric dispersion, and deposition, Atmos.
Chem. Phys., 12, 2313-2343, doi:10.5194/acp-12-2313-2012, 2012.

TEPCO (Tokyo Electric Power Co., Inc.): Estimation of additional emissions from nuclear reactor buildings (30 July 2012), available at: http://www.tepco.co.jp/nu/fukushima-np/roadmap/ images/m120730_05-j.pdf (last access: 26 July 2016), 2012 (in Japanese).

TEPCO: Estimation of the additional emission from nuclear reactor buildings (30 May 2013), available at: http://www.tepco.co. jp/nu/fukushima-np/roadmap/images/d130530_05-j.pdf (last access: 26 July 2016), 2013 (in Japanese).

TEPCO: Estimation of the additional emission from nuclear reactor buildings (27 March 2014), available at: http://www.tepco.co. jp/nu/fukushima-np/roadmap/images/d140327_06-j.pdf (last access: 26 July 2016), 2014a (in Japanese).

TEPCO: Estimation of the additional emission from nuclear reactor buildings (25 December 2014), available at: http://www.tepco. co.jp/nu/fukushima-np/roadmap/images/d141225_08-j.pdf (last access: 26 July 2016), 2014b (in Japanese).

TEPCO: Estimation of radioactive material released during debris removal operations at reactor unit 3 of the Fukushima Daiichi Nuclear Power Plant in August 2013, available at: http://www. nsr.go.jp/data/000051136.pdf (last access: 26 July 2016), 2014c (in Japanese).

TEPCO: Estimation of the additional emission from nuclear reactor buildings (9 October 2015), available at: http://www.tepco.co. jp/life/custom/faq/images/d151109_11-j.pdf (last access: 26 July 2016), 2015 (in Japanese).

Terada, H., Katata, G., Chino, M., and Nagai, H.: Atmospheric discharge and dispersion of radionuclides during the Fukushima Dai-ichi Nuclear Power Plant accident, Part II: Verification of the source term and analysis of regional-scale atmospheric dispersion, J. Environ. Radioact., 112, 141-154, 2012.

Tsuruta, H., Oura, Y., Ebihara, M., Ohara, T., and Nakajima, T.: First retrieval of hourly atmospheric radionuclides just after the Fukushima accident by analysing filter-tapes of operational air pollution monitoring stations, Scientific Reports, 4, 6717, doi:10.1038/srep06717, 2014.

Uliasz, M.: Development of the mesoscale dispersion modelling system using personal computers, Part I: Models and computer implementation, Z. Meteor., 40, 110-120, 1990.

Wesely, M. L. and Hicks, B. B.: A review of the current status of knowledge on dry deposition, Atmos. Environ., 34, 2261-2282, 2000 .

Winiarek, V., Bocquet, M., Saunier, O., and Mathieu, A.: Estimation of errors in the inverse modeling of accidental release of atmospheric pollutant: Application to the reconstruction of the cesium-137 and iodine-131 source terms from the Fukushima Daiichi power plant, J. Geophys. Res., 117, D05122, doi:10.1029/2011JD016932, 2012.

Winiarek, V., Bocquet, M., Duhanyan, N., Roustan, Y., Saunier, O., and Mathieu, A.: Estimation of the caesium-137 source term from the Fukushima Daiichi nuclear power plant using a consistent joint assimilation of air concentration and deposition observations, Atmos. Environ., 82, 268-279, 2014.

Yasunari, T. J., Stohl A., Hayano R. S., Burkhart J. F., Eckhardt S., and Yasunari T.: Cesium-137 deposition and contamination of Japanese soils due to the Fukushima nuclear accident, P. Natl. Acad. Sci. USA, 108, 19530-19534, 2011. 
Yumimoto, K., Morino, Y., Ohara, T., Oura, Y., Ebihara, M., Tsuruta, H., and Nakajima, T.: Inverse modeling of the 137Cs source term of the Fukushima Dai-ichi Nuclear Power Plant accident constrained by a deposition map monitored by aircraft, J. Environ. Radioact., 164, 1-12, 2016. 